\title{
QUEST FOR ROBUST OPTIMAL MACROPRUDENTIAL POLICY
}

Pablo Aguilar, stephan Fabr, Eddie Gerba. and Samuer huntado.

Documentos de Trabajo. N. 1916

\section{BANCODE ESPAÑA}

Eurosistema

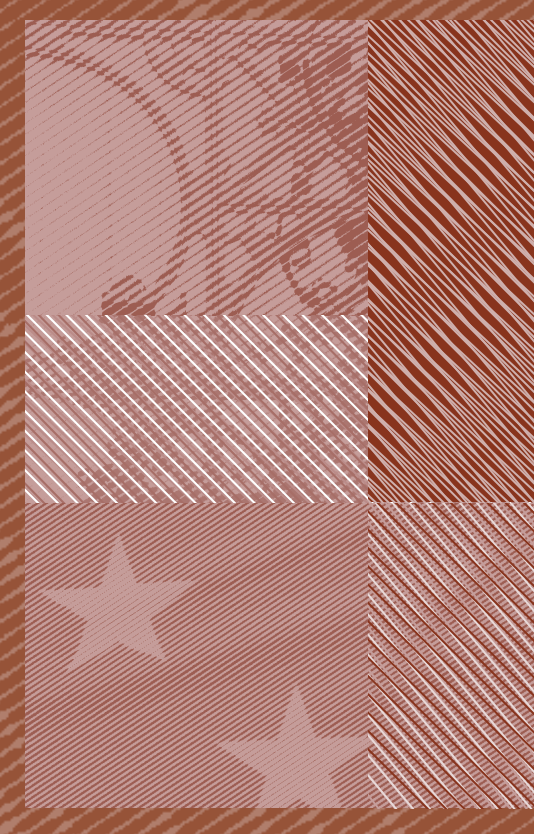


QUEST FOR ROBUST OPTIMAL MACROPRUDENTIAL POLICY 
QUEST FOR ROBUST OPTIMAL MACROPRUDENTIAL POLICY(*)

Pablo Aguilar and Samuel Hurtado

BANCO DE ESPAÑA

Stephan Fahr

EUROPEAN CENTRAL BANK

Eddie Gerba

DANMARKS NATIONALBANK

(*) Aguilar: Economist, Banco de España, ES-28014 Madrid. Fahr: Principal Financial Stability Expert, European Central Bank, DE-60314 Frankfurt am Main. Gerba: Advisor, Danmarks Nationalbank, DK-1093, Copenhagen. Hurtado: Economist, Banco de España, ES-28014 Madrid. Corresponding author: pablo.aguilar@bde.es. The paper is forthcoming in Banco de España and Dynare Working Paper series. The views expressed in this paper are solely ours and should not be interpreted as reflecting the views of the ECB, Banco de España, Danmarks Nationalbank, nor those of the ESCB as a whole. 
The Working Paper Series seeks to disseminate original research in economics and finance. All papers have been anonymously refereed. By publishing these papers, the Banco de España aims to contribute to economic analysis and, in particular, to knowledge of the Spanish economy and its international environment.

The opinions and analyses in the Working Paper Series are the responsibility of the authors and, therefore, do not necessarily coincide with those of the Banco de España or the Eurosystem.

The Banco de España disseminates its main reports and most of its publications via the Internet at the following website: http://www.bde.es.

Reproduction for educational and non-commercial purposes is permitted provided that the source is acknowledged.

C BANCO DE ESPAÑA, Madrid, 2019

ISSN: 1579-8666 (on line) 


\section{Abstract}

This paper contributes by providing a new approach to study optimal macroprudential policies based on economy wide welfare. Following Gerba (2017), we pin down a welfare function based on a first-and second order approximation of the aggregate utility in the economy and use it to determine the merits of different macroprudential rules for Euro Area. With the aim to test this framework, we apply it to the model of Clerc et al. (2015). We find that the optimal level of capital is 15.6 percent, or 2.4 percentage points higher than the 2001-2015 value. Optimal capital reduces significantly the volatility of the economy while increasing somewhat the total level of welfare in steady state, even with a time-invariant instrument. Expressed differently, bank default rates would have been 3.5 percentage points lower while credit and GDP 5\% and 0.8\% higher had optimal capital level been in place during the 2011-2013 crisis. Further, using a model-consistent loss function, we find that the optimal Countercyclical Capital Buffer (CCyB) rule depends on whether observed or optimal capital levels are already in place. Conditional on optimal capital level, optimal CCyB rule should respond to movements in total credit and mortgage lending spreads. Gains in welfare from optimal combination of instruments is higher than the sum of their individual effects due to synergies and positive mutual spillovers.

Keywords: optimal policy, global welfare analysis, financial stability, financial DSGE model, macroprudential policy.

JEL classification: G21, G28, G17, E58, E61. 


\section{Resumen}

Este artículo propone una nueva aproximación al análisis de las políticas macroprudenciales basado en el bienestar de la economía. En línea con Gerba (2017), fijamos una función de bienestar con criterios de primer y segundo orden ligados a la utilidad agregada de la economía para determinar los beneficios de distintas reglas macroprudenciales en la zona del euro. Esta propuesta es evaluada en el marco del modelo de Crec et al. (2015). Los resultados muestran que el nivel de capital óptimo es de un 15,6\%, 2,4 puntos porcentuales por encima de la media del período 2001-2015. Situándose los requisitos de capital en su nivel óptimo se reduce significativamente la volatilidad de la economía, a la vez que aumenta el nivel de bienestar a largo plazo, aun siendo un instrumento invariante en el tiempo. Dicho de otro modo, bajo el nivel óptimo de capital el porcentaje de quiebras bancarias hubiera sido 3,5 puntos porcentuales menor, y el crédito y el PIB, un $5 \%$ y un 0,8\% mayores respectivamente, durante la crisis de 2011-2013. Además, con el uso de una función de pérdidas consistente con el modelo, encontramos que la regla para el colchón de capital contracíclico (CCyB) depende de si la economía se encuentra en su nivel óptimo de capital o no. Condicionado a esto último, los resultados sugieren que el CCyB óptimo debe responder a movimientos en el crédito y en los diferenciales hipotecarios. Además, las ganancias en términos de bienestar resultan mayores cuando la determinación de ambas herramientas macroprudenciales es conjunta gracias a las sinergias que se generan.

Palabras clave: política macroprudencial óptima, análisis de bienestar, estabilidad financiera, modelos de equilibrio general.

Códigos JEL: G21, G28, G17, E58, E61. 
Following the Great Financial Crisis (GFC) in 2008, a set of macroprudential tools have been designed and implemented to contain and reduce systemic risks, increase the soundness of the financial system, and prevent a repetition of the sharp reversal observed in 2007-08. Capital-based measures currently represent the cornerstone of the macroprudential toolkit, and because of that several academic papers have assessed the impact of adjusting capital requirements on the resilience of the banking sector and costs to banks in terms of financing costs, external financing spreads, credit supply, and financing flexibility. While important and relevant, those studies often take a reduced-form view on the costs and benefits, and allow a lot of space for subjective evaluation of net benefits.

This paper takes a different approach and examines the net benefits from a comprehensive and systematic viewpoint. Recognising that these measures have both benefits and costs, the approach taken here weights these in an objective and model-consistent manner, and evaluates net benefits for the totality of the economy. In particular, we take the method developed in the monetary policy literature on optimal rules (see for example Woodford (2003) or Gali and Monacelli (2004)), and adapt it to the particularities of macroprudential policy.

This paper builds on this literature by providing analytical, model-consistent and easily quantifiable welfare criteria that are then used to derive optimal macroprudential policies. First we analytically derive a second-order welfare criterion that incorporates both long-run level and shorter-run volatility effects, and use it to find the optimal level of capital requirements. Next, we derive a loss function that only includes second order terms, and use it to search for an optimal countercyclical buffer $(\mathrm{CCyB})$ rule. ${ }^{1}$ The third and final section examines the interaction between these two capital-based measures, and finds that the shape of the optimal CCyB rule changes depending on whether the capital requirement has already been set to its optimal level. Together with the finding that suboptimal specifications or parameters can easily lead to welfare losses relative to inaction, this is an indication that $\mathrm{CCyB}$ rules are more difficult to implement, since the optimal specification and parameters depend on whether other policies have already been implemented. To test its' performance, the method is applied to the medium-scale financial DSGE model of Clerc et al (2015) involving six types of agents, where three of them can endogenously default (banks, borrower households, and entrepreneurs).

The paper is particularly relevant for policy-makers since it provides a novel analytical avenue on how to design, calibrate, and evaluate the impact of macro-

\footnotetext{
${ }^{1}$ Analogous to a Taylor rule for monetary policy, this instrument responds to cyclical deviations in certain variables, and its ability to influence the economy should be in the short- and medium-run only.
} 
prudential measures. Moreover, it provides a framework that allows regulators to compare and assess, in terms of welfare losses, how close or far away the current implemented measures are from that optimum level. In some cases, because welfare is not observable, policymakers may prefer to use quantifiable variables such as GDP, credit, or probability of crisis in order to measure the effects of implemented macropudential policy instruments; this framework is flexible enough to compare these alternative instruments to the optimal. Finally, counterfactual scenarios can be simulated (and we do so in this paper) to show the economic performance that would have materialized had optimal instruments been activated in the first place.

Our main results are: First, the optimal level of risk-weighted capital for Euro Area is 15.6 percent. This is 2.4 percentage points higher than the average level observed during the 2001-2015 period. And we find that setting the capital level 'too high' is more forgiving than setting it 'too low': while the welfare is only marginally reduced when deviating to the right of the optimal level (overshooting), the reduction in welfare is much higher when deviating to the left (undershooting). This is important because in real time the policy-maker will always hold imperfect information regarding the contemporaneous economic structure and shocks. Second, the optimal EA CCyB rule is one that responds to developments in total credit and house prices. However, this result rests on the premise that the exact weights in the rule are implemented since the area of admissible coefficients is very narroiw. In other words, weight misspecification can generate significant welfare costs and so great attention should be placed in applying the exact optimal weights. Third, once an optimal capital level has been implemented, the range of permissible weights in the $\mathrm{CCyB}$ rule that expands, which reduces the probability of misspecifying the CCyB, making it more robust. In addition, the optimal $\mathrm{CCyB}$ rule changes to one that responds to total credit and mortgage lending spreads. Also global welfare is in this case considerably higher compared to the sum of welfare gains that the two optimal policies generate separately. This means that one optimal policy exerts positive externalities on the other and generate positive synergies, which results in higher joint gains. Fourth and final, we show that, according to the model, credit and GDP losses since the GFC would have been significantly smaller (between 7 and $13 \%$ for credit and $1.25 \%$ for GDP) and the default probability of banks could have been greatly reduced (by up to 3.6 percentage points), had the authorities implemented the optimal combination of capital-based instruments in the first place.

The rest of the paper is organised as follows. Section 1 provides a conceptual discussion on the role of macroprudential policy using existing literature and motivates for macroprudential policy in the model of Clerc et al (2015) by highlighting 
some key distortions it attempts to correct. Section 2 discusses the optimal level of capital by first deriving a model-implied and utility-based optimality criterion and then testing it within this particular framework. We also compare it to alternative simpler criteria popular in policy circles. Section 3 considers optimality criteria for the setting of optimal countercyclical buffers and searches for specific examples. Section 4 discusses the interaction between the optimal level of capital and the optimal CCyB rules. Lastly, section 5 concludes.

\section{The role of macroprudential policy}

Literature on macroprudential policy is relatively new but quickly growing. The main challenge has been to provide the fundamental building blocks to accommodate for a system-wide financial policy in a general equilibrium framework. The current debate can be synthesized under two streams, where (at the moment), the first one has been discussed and used more widely to motivate the need for a system-wide financial intervention.

The first line of research focuses on the negative pecuniary externalities that financial contracts, financial decisions and interactions between banks cause because they do not take into account the wider (or later) impact of their actions on the financial system, or the economy (Davila and Korinek (2017)). De Nicolo, Favara and Ratnovski (2012) categorize these externalities into three types: externalities related to strategic complementarities, externalities related to interconnectedness, and externalities related to fire sales. The first type arises as a result of strategic interactions between financial intermediaries and may lead to a build-up in systemwide vulnerabilities, in particular during a financial boom. The second variety of externality arises as a result of the tight and complex network that exists between financial actors, which can easily propagate (small) negative shocks throughout the entire system. The third type is caused by a broad sell-off in assets during financial downturns, which leads to a heavy drop in asset prices and balance sheets of financial intermediaries. Following from these distortions, Mendoza (2016 and Bianchi and Mendoza (2018) show how macroprudential tools such as loan-to-value or loan-toincome ratios can, much like taxes, correct for them and internalize (at least) some of these externalities.

The second research stream focuses on the aggregate demand externalities that agents exercise on others when signing financial contracts. Ex ante, agents do not take into account the externalities their asset positions have on aggregate demand in

the future. Under nominal rigidities and constrained monetary policy (by the zero 
lower bound) this distortion can have quantitatively large effects on future demand, and the general equilibrium becomes constrained inefficient. Fahri and Werning (2016) provide an exact way to calculate this externality as well as the tax that is required to correct for it. This tax can, from an ex ante point of view, be viewed as a macroprudential tool since it incentivizes or penalizes particular behaviour or contracts.

Despite their differences in type of distortions and channels, the role of macroprudential policy is akin to that of fiscal policy in both streams. The rationale for the use of policy is very similar to that of Pigouvian taxes, and they generate high redistributive effects. While in practice that is easy to relate with borrower-based measures such as loan-to-value/income, debt-to-value/income, or even total-debtservice-ratio, the link to capital-based measures is not as straight-forward. In particular, capital-based tools do not directly affect the income or value of borrowers, but has rather an impact on the decision and quantity of loans supplied, as well as the willingness of savers to deposit. The key variable that these measures are (preventivly) aiming at minimizing is the expected probability of default of banks. As shown in the previous section, capital requirements aim at keeping this probability as low as possible such that the default event never materializes at any point in the future. However, since risks build up over the cycle, additional measures need to be employed in order to tackle these cyclical hazards, which in turn may increase the overall default probability. For that, $\mathrm{CCyB}$ is especially tailored to take into account these time-varying risks. Albeit these measures do not restrain the borrowers' fiscal position directly, indirectly they do by determining their liquidity (money) holdings, which has some redistributive effects. Moreover, at the heart of the financial dynamics (and the default probability) is the bank's incentive to lever up and overextend credit from a social perspective. Taking this into account, the motivation for macroprudential policy in this model seems to be closer to that of the first strand, in particular to the externalities related to strategic complementarities. ${ }^{2}$

\subsection{Motivation for macroprudential policy}

The best way to test a method is to apply it to a specific framework. For this purpose, we have chosen the dynamic structural model of Clerc et al. (2015) because it is constructed with Euro Area banking sector and financing specificities in mind as well as because it provides an explicit rationale for capital regulation by introducing two types of distortions: limited liability on the part of banks, and bank funding

\footnotetext{
${ }^{2}$ Moreover, this model lacks nominal rigidities and a monetary policy which could potentially amplify a distortion.
} 
cost externalities resulting in excessive risk-taking by banks. The model introduces financial intermediaries and three layers of default into an otherwise standard dynamic stochastic general equilibrium (DSGE) framework, but absent nominal and real rigidities. While in this model defaults can occur among banks, non-financial corporations and households, the key default that triggers macroprudential policy is that of banks.

The model includes six types of representative agents: borrowers, savers, entrepreneurs, banks, bankers, and the macroprudential authority. However, because the focus of the model is on financial relations, the majority of the dynamics is concentrated to the banking sector. Banks finance their loans by raising equity (from bankers) and deposits (from savers). Deposits are formally insured by a deposit insurance agency that is funded by lump-sum taxes paid by savers and borrowers. When banks default (a non-linear event) depositors suffer some transaction costs despite the deposit insurance scheme. This feature effectively links bank risk to banks' funding costs. ${ }^{3}$

However, banks' cost of funding is not related to banks' individual risk taking. Instead, it is dependent on the system-wide risk pattern. This is due to two factors. First, safety-net guarantees insulate banks' cost of deposits from the effect of their individual risk taking. Second, the deposit premium is based on system-wide bank risk failure. This reduces the incentive of any individual bank to limit leverage and failure risk because it will get no funding cost premia (benefit) when depositors are assumed to be imperfectly informed.

Moreover, banks have an incentive to take as much risk as possible by leveraging up to the regulatory limit. This excessive leverage has two counter-acting effects on their funding costs in equilibrium. On one hand, default probability of banks increases, which exerts upward pressure on banks' funding costs. On the other, this results in higher bailout subsidy (and taxes), which puts downward pressure on their funding costs. The net effect depends on which of the two dominates. If overall bank failure risk is high, the first effect (higher deposit premium) dominates, and the excessive leverage depresses economic activity. If overall bank risk is low, excessive leverage will support economic activity. Economising on expensive equity reduces overall bank funding costs, and higher leverage will increase economic activity.

Higher capital ratios tighten the supply of loans by reducing the incentives for banks to take on excessive leverage. At the same time, higher capital ratios reduce the cost of uninsured funds provided to banks, which in turn reduces the cost of credit. The final impact depends on which of the two channels dominates. Moreover,

\footnotetext{
${ }^{3}$ For a detailed description of the model structure, see the original Clerc et al (2015) paper.
} 
the heterogeneity in households means that there is a trade-off between the welfare of savers and borrowers. In the long run, savers benefit from tighter capital regulation due to the reduced likelihood of bank failures which implies safer bank deposits. Borrowers, meanwhile, lose out after a certain level of capital, as this leads to a reduced supply of loans. Because of these multiple trade-offs, the model is well-suited to detect an optimal level (and combination) of policy since there is a well-identified global welfare function. In addition, once the optimal policy has been identified, it can be used to calculate the general equilibrium effects from such policy (mix), as well as extract the precise gains (distance) from alternative scenarios (involving alternative policy options or no policy at all). Our method is originally inspired by the one used for optimal monetary policy (see Woodford (2003), De Fiore and Tristani (2009), Gerba (2017) or Ferrero et al (2018), but with some important modifications and adaptations to take into account the differences in objectives, targets, and instruments used in macroprudential policy and financial stability.

\section{$1.2 \quad$ Key mechanisms}

The key mechanisms and trade-offs relevant to the welfare analysis are within the banking sector. In the next few lines, we will proceed to describe the composition of bank liabilities, as well as the regulatory requirements.

The aggregate default rate for the banking system, $P D_{t}^{b}$, which is also the fraction of deposits in banks that fail in period $t$ is determined by:

$$
P D_{t}^{b}=\frac{d_{t-1}^{H} P D_{t}^{H}+d_{t-1}^{F} P D_{t}^{F}}{d_{t-1}^{H}+d_{t-1}^{F}}
$$

where $P D_{t}^{H}$ is the default rate for borrowing households, $P D_{t}^{F}$ that of firms,

$d_{t-1}^{H}$ is the share of deposits lent out to borrowing households, and $d_{t-1}^{F}$ the share lent out to entrepreneurs. The average default rate of banks is the weighted average of the default rates of the creditors (borrowers and entrepreneurs). This rate, in turn, determines the interest rate on deposits since savers demand a risk premium on their deposits depending on the (average) default rate of banks according to:

$$
\tilde{R_{t}^{D}}=R_{t-1}^{D}+\left(1-\gamma P D_{t}^{b}\right)
$$

Notice the time-dependency of the deposit rate, but in extreme cases (when $P D_{t}^{b}$ is very high) it can become non-linear and significantly deviate from previous periods deposit rate.

Note also that in this model, the probability of households' default on their loans, and by extension that of banks on its deposits is dependent on both an idiosyncratic 
and an aggregate shock. Thus, the debt is not state-contingent, and loan and deposit contracts are incomplete insofar that they can't be made contingent on aggregate variables., Thus, while the debt contract shields against idiosyncratic shocks, it is directly affected the aggregate shock, through $R_{t}^{H}$ that is the ex post average realized gross return on housing:

$$
R_{t}^{H}=\frac{q_{t}^{H}\left(1-\delta_{t}^{H}\right.}{q_{t-1}^{H}}
$$

In turn, the deposits held by savers must equal the sum of the demand for deposit funding from the banks making loans to households, $d_{t-1}^{H}=\left(1-\phi_{t}^{H}\right)\left(q_{t}^{H} h_{t}^{m} x_{t}^{e} / R_{t}^{m}\right)$, and from the banks extending loans to entrepreneurs, $d_{t-1}^{F}=\left(1-\phi_{t}^{F}\right)\left(q_{t}^{K} k_{t}-(1-\right.$ $\left.\left.\chi^{e}\right) W_{t}^{e}\right)$, that is:

$$
d_{t}=d_{t-1}^{F}+d_{t-1}^{H} \equiv\left(1-\phi_{t}^{F}\right)\left(q_{t}^{F} k_{t}-\left(1-\chi^{e}\right) W_{t}^{e}\right)+\left(1-\phi_{t}^{H}\right)\left(q_{t}^{H} h_{t}^{m} x_{t}^{e} / R_{t}^{m}\right)
$$

To continue with deposits, the losses caused by the failing borrowers and entrepreneurs are given by:

$$
T_{t}^{H}=\left[\overline{\omega_{t}^{H}}-\Gamma^{H}\left(\overline{\omega_{t}^{H}}\right)+\mu^{H} G^{H}\left(\overline{\omega_{t}^{H}}\right) \tilde{R_{t}^{H}} \frac{q_{t-1}^{H} h_{t-1}^{m} x_{t-1}^{e}}{R_{t-1}^{m}}\right]
$$

and

$$
T_{t}^{F}=\left[\overline{\omega_{t}^{F}}-\Gamma^{F}\left(\overline{\omega_{t}^{F}}\right)+\mu^{F} G^{F}\left(\overline{\omega_{t}^{F}}\right) \tilde{R}_{t}^{F}\left[q_{t-1}^{K} k_{t-1}\left(1-\chi^{e}\right) W_{t}^{e}\right](6)\right.
$$

that are covered with lump-sum taxes imposed on savers in order to fully cover for the losses in each period $T_{t}=T_{t}^{H}+T_{t}^{F}$.

The other source of funding for banks, equity, is more costly and therefore supplied in less quantity to banks. Total equity provided by bankers, $n=(1-(1-$ $\left.\left.\chi^{e}\right) W_{t}^{b}\right)$ must equal the sum of the demand for bank equity for loans to borrowers, $e_{t}^{H}=\phi_{t}^{H}\left(q_{t}^{H} h_{t}^{m} x_{t}^{e} / R_{t}^{m}\right)$ and loans to entrepreneurs, $e_{t}^{F}=\phi_{t}^{F}\left(q_{t}^{K} k_{t}-\left(1-\chi^{e}\right) W_{t}^{e}\right)$ :

$$
\left(1-\chi^{e}\right) W_{t}^{b}=\phi_{t}^{F}\left[\left(1-\chi^{e}\right) W_{t}^{e}\right]+\phi_{t}^{H} \frac{q_{t-1}^{H} h_{t-1}^{m} x_{t-1}^{e}}{R_{t-1}^{m}}
$$

You will notice that, because equity is more expensive, the share of equity financing, $\phi_{t}$ is minimal, and in steady state, just enough to cover the regulatory capital requirements (since only equity can be used as eligible regulatory capital).

To conclude, we need to describe the characteristics and evolution of regulatory capital. The total capital buffer, $\phi_{t}^{j}$ consists of a structural (time-invariant) $\bar{\phi}_{o}^{j}$ and a cyclical component $\bar{\phi}_{t}^{j}$.

$$
\phi_{t}^{j}=\bar{\phi}_{0}^{j}+\bar{\phi}_{t}^{j}\left[\log \left(\Sigma_{t}\right)-\log \left(\Sigma_{0}\right)\right]
$$


We call the second component a Countercyclical Capital Buffer (CCyB) that depends on the state of the economy. We will in the subsequent sections discuss what particular indicators of the (financial) cycle the rule should optimally respond to. For the moment, we generally describe it as responding to deviations of a number of (indicator) variables $\Sigma$ from their trend (or steady state) values. In the next section, we will also examine the optimal level of the structural component. Note that the rule prescribes an additive approach to regulatory capital (in line with Basel III), where the cyclical part is on top of the structural component, and not as a substitute for it. Moreover, what we call here regulatory capital $\phi_{t}^{j}$ is actually the ratio of equity-to (risk weighted) assets. Therefore, this variable can also be written as:

$$
\phi_{t}^{j}=\frac{e_{t}^{F}+e_{t}^{H}}{\left(1-\chi^{e}\right) W_{t}^{e}}+\frac{q_{t-1}^{H} h_{t-1}^{m} x_{t-1}^{e}}{R_{t-1}^{m}}
$$

In the current model version, loans to borrowers (or borrowing households) has a higher risk weight, and therefore will matter, in relative terms, more for the risk profile of banks, and macroprudential policy setting.

\section{Optimal capital requirements}

\subsection{Optimality and global welfare function}

It is not a priori clear whether the policy-maker wishes to impose a low or high capital requirement. On one hand, high capital requirements lead to a low credit level, much below the social optimum. On the other hand, a very low capital requirement may lead to excessive bank leverage, which may take the entire economy into a default state. Moreover, the effects may be non-linear with respect to different levels of capital. Hence, the policy-maker (or social planner) should balance the two forces, and take into account the fiscal costs involved in bank default.

The most comprehensive way to extract optimal bank capital levels is to subject it to a welfare criterion that is global, model-consistent, and derived from the model's first principles. Only then can one genuinely speak of a vigorous optimal capital ratio since that is the level that maximizes welfare of all consumers in the economy. To find the criterion, we derive a first-and second order approximation of aggregate utility. Both household types are considered when constructing the aggregate utility measure. The objective of the macroprudential authority is to find the capital level that maximizes the level of (aggregate) utility while at the same time minimizing the volatility of its' arguments. That is why we capture both a first- (level) and second order (volatility) term in the global welfare expression. The first order terms 
are all added in order to collect all level-effects, while the second order terms are all subtracted in order to subtract any changes in the volatility of the aggregate utility following implementation of a policy. Because of the inherent trade-offs in banks' lending activity, the welfare measure is expected to be hump-shaped with a (local or global) maximum. In the following subsection, we will show the steps to derive this function.

\subsubsection{Deriving the utility-based welfare function}

Households are the only consumers in our setting. Thus, the policy objective function will be a weighted average of the (approximate) utility function of saver-and borrower households, or:

$$
E_{0} \sum_{i=0}^{\infty} \beta^{t+i}\left[\zeta U_{t}^{s}+(1-\zeta) U_{t}^{m}\right]
$$

where $\zeta$ is the weight of the utility of savers in the policy objective. The two utility functions are:

$$
E_{0} \sum_{i=0}^{\infty} \beta_{t+i}^{s}\left[\log c_{t+1}^{s}+\nu^{s} \log h_{t+i-1}^{s}-\frac{\varphi^{s}}{1+\eta}\left(l_{t+i}^{s}\right)^{1+\eta}\right]
$$

for savers, and for borrowers:

$$
E_{0} \sum_{i=0}^{\infty} \beta_{t+i}^{m}\left[\log c_{t+1}^{m}+\nu^{m} \log h_{t+i-1}^{m}-\frac{\varphi^{m}}{1+\eta}\left(l_{t+i}^{m}\right)^{1+\eta}\right]
$$

,where $\beta^{s}>\beta^{m}$.

After derivations in Appendix I, we find that the above expression can be approximated and re-written to only include first-and second order additive terms according to:

$$
E_{0} \sum_{i=0}^{\infty} \beta^{t+i}\left(U_{t}-U\right)=E_{0} \Sigma_{i=0}^{\infty} \beta^{t+i} W^{f}+t . i . p+O^{3}
$$

with $W^{f}=\chi_{h^{s}} \mu_{h^{s}}-\chi_{h^{s}}^{2} \sigma_{h^{s}}^{2}+\chi_{h^{m}} \mu_{h^{m}}-\chi_{h^{m}}^{2} \sigma_{h^{m}}^{2}+\chi_{w} \mu_{w}-\chi_{w}^{2} \sigma_{w}^{2}+\chi_{k} \mu_{k}-\chi_{k}^{2} \sigma_{k}^{2}$

where $\chi_{h^{s}} \equiv \zeta \frac{\nu^{s}}{h^{s}}-\frac{\left(1+g^{h}\right)}{I^{h}}\left[-\left(1-\delta^{h}\right)\right]$,

$\chi_{h^{s}}^{2} \equiv \zeta \frac{\nu^{s}}{h^{s}}-\frac{\left(1+g^{h}\right)}{I^{h}}\left[-\left(1-\delta^{h}\right)\right]$,

$\chi_{h^{m}} \equiv(1-\zeta) \frac{\nu^{m}}{h^{m}}-\frac{\left(1+g^{h}\right)}{I^{h}}\left[-\left(1-\delta^{h}\right)\right]$,

$\chi_{h^{m}}^{2} \equiv(1-\zeta) \frac{\nu^{m}}{h^{m}}-\frac{\left(1+g^{h}\right)}{I^{h}}\left[-\left(1-\delta^{h}\right)\right]$,

$\chi_{w} \equiv \frac{1+\eta}{\left(\varphi^{s}+\varphi^{m}\right)(1-\alpha)} \frac{w w \eta_{s s}^{2}}{2}$,

$\chi_{w}^{2} \equiv \frac{1+\eta}{\left(\varphi^{s}+\varphi^{m}\right)(1-\alpha)}$,

$\chi_{k} \equiv-\frac{1+g}{I}+\delta_{t}$,

and $\chi_{k}^{2} \equiv-\frac{1+g}{I} \frac{1}{I} \delta_{t}+\frac{1}{2} \frac{l^{2} \delta}{2}$. 
Using the calibrated values for the Euro Area explained in Clerc et al (2015), and extracting the steady state values for the endogenous variables, we find the following optimal weights for each of the arguments in the loss function:

$$
\begin{gathered}
\chi_{h^{s}} \equiv 3 \\
\chi_{h^{s}}^{2} \equiv 3 \\
\chi_{h^{m}} \equiv 3 \\
\chi_{h^{m}}^{2} \equiv 3 \\
\chi_{w} \equiv 1.43 \\
\chi_{w}^{2} \equiv 0.05 \\
\chi_{k} \equiv-0.8 \\
\chi_{k}^{2} \equiv 0.005
\end{gathered}
$$

Normalizing to 1 for $\chi_{h_{m}}$ and $\chi_{h_{m}}^{2}$, the respective weights become:

$$
\begin{gathered}
\chi_{h^{s}} \equiv \frac{3}{3}=1 \\
\chi_{h^{s}}^{2} \equiv \frac{3}{3}=1 \\
\chi_{h^{m}} \equiv \frac{3}{3}=1 \\
\chi_{h^{m}}^{2} \equiv \frac{3}{3}=1 \\
\chi_{w} \equiv \frac{1.43}{3}=0.48 \\
\chi_{w}^{2} \equiv \frac{0.05}{3}=0.02 \\
\chi_{k} \equiv \frac{-0.8}{3}=-0.27 \\
\chi_{k}^{2} \equiv \frac{0.005}{3}=0.002
\end{gathered}
$$


This is the welfare function we use as objective criterion in our experiments to find the optimal bank capital levels for Euro Area. Again, the optimal capital level is the one that maximizes this objective function. The weights of each argument in the welfare function are determined by the values in the calibration exercise for the 2001-14 period. If the calibrated values change, the weights will also change.

\subsubsection{Alternative optimality criteria}

An alternative to our approach would have been to compute directly the welfare gains associated with any particular policy as a weighted average of the consumptionequivalent gains of each household dynasty under the baseline policy (with capital on firm loans twice as high as that on household loans) equal to the welfare under alternative values of both capital ratios. The weight on each individual dynasty is given by the share of that dynasty in aggregate consumption under the baseline policy. The reported welfare gains would then be equal to:

$$
\Delta W \equiv \frac{c_{0}^{s}}{c_{0}^{s}+c_{0}^{m}} \Delta^{s}+\frac{c_{0}^{m}}{c_{0}^{s}+c_{0}^{m}} \Delta^{m}
$$

$c_{0}$ denotes the steady-state consumption of each dynasty under the baseline policy. While this measure is straight-forward (and hence why we compare our results to it), it suffers from a number of drawbacks. First, the policy-maker does not directly control agents' consumption. Hence, his knowledge of the consumption dynamics is imperfect. Second, determining the share of each household dynasty (in turn which dynasty matters more) becomes a subjective choice. Moreover, determining the share by the contribution of each to aggregate consumption under the baseline policy is misguiding as this share may endogenously change due to policymakers undertaking alternative policies, as well as with the key policy parameters. Third, the policy-maker would, in his welfare criterion, like to use variables that are directly affected by default distortion and financial frictions. Fourth (and maybe most important) consumer utility is determined by other factors besides consumption. If one only considers consumption (levels and volatility), one may disregard other factors that contribute to their total welfare.

For robustness purposes, we also compare our results to alternative ad hoc objective criteria that are often used (in practice) for determining the level of capital. Examples of these criteria are: number of bank defaults, GDP losses, investment losses, consumption losses, gains in utility of borrowers, or gains in utility of savers. The aim is to contrast the capital levels prescribed by these criteria to our global welfare criterion above, including a full comparison of the trade-offs and effects that these alternative capital levels have on the economy. 


\subsection{Quantitative results}

\subsubsection{Optimal capital level}

In this section we evaluate the welfare gains with distinct levels of capital. In other words, we are depicting the welfare function for a range of values of capital requirements.

Graph 1 shows the percentage change in welfare relating to various capital levels in relation to the level observed during the 2001-15 period. The historical average level was $13.2 \%$, while we compare it to capital levels ranging from 10 to $18 \%$.

The graph shows that welfare initially improves quickly as we increase capital levels, but that the rate of improvement drops once we approach the historical average. Nevertheless, it continues to increase even after that level, and reaches a maximum at around $15.6 \%$. At this level, the welfare is $10 \%$ higher compared to the historical average. Since this is a (local) welfare maximum for reasonable levels of capital, we consider $15.6 \%$ to be the optimal capital level for Euro Area. In addition, the shape of the welfare function suggests that, it is safer for macroprudential authority to overshoot in setting the right capital level rather than undershoot. The drop in welfare gains is significantly steeper to the left of the optimum compared to the right of it. That means that the effects are indeed non-linear as capital levels increase. Our welfare function can in a simple but holistic way capture them. Although a bit more cumbersome, one can also view these asymmetric effects through the individual macro-financial variables in the next figure. The percentage change in the various variables at lower levels of capital and to the left of the optimum are much higher then to the right, confirming this cost of 'undershooting'.

Putting these numbers into broader perspective will be helpful. In particular, we wish to compare the broader economic (steady-state) effects that capital levels from 10 to $18 \%$ have. At the same time, this allows us to contrast the general equilibrium effects from the welfare criterion-based capital levels to those that would be prescribed from more myopic or partial criteria such as the number of defaults of banks or household consumption. This is also a more direct way to check whether the welfare function-based optimum is as holistic as we claim and whether it succeeds in balancing numerous trade-offs that are embedded within banks' lending activity. Figure 2 depicts these effects.

An increase in capital levels that takes them from their historical average to the optimal value (an increase of approximately 2.4 p.p.) would make banks reduce total credit to meet the capital requirements, but, given the difference in the risk

\footnotetext{
${ }^{4}$ The only exceptions are some firm-related variables such as NFC loans and business investment where the rate of change in those is almost the same to the left and right of the optimum.
} 
Figure 1: Capital levels for Euro Area using the objective welfare function

\section{Euro Area - Comparative Statics wrt Capital requirement}

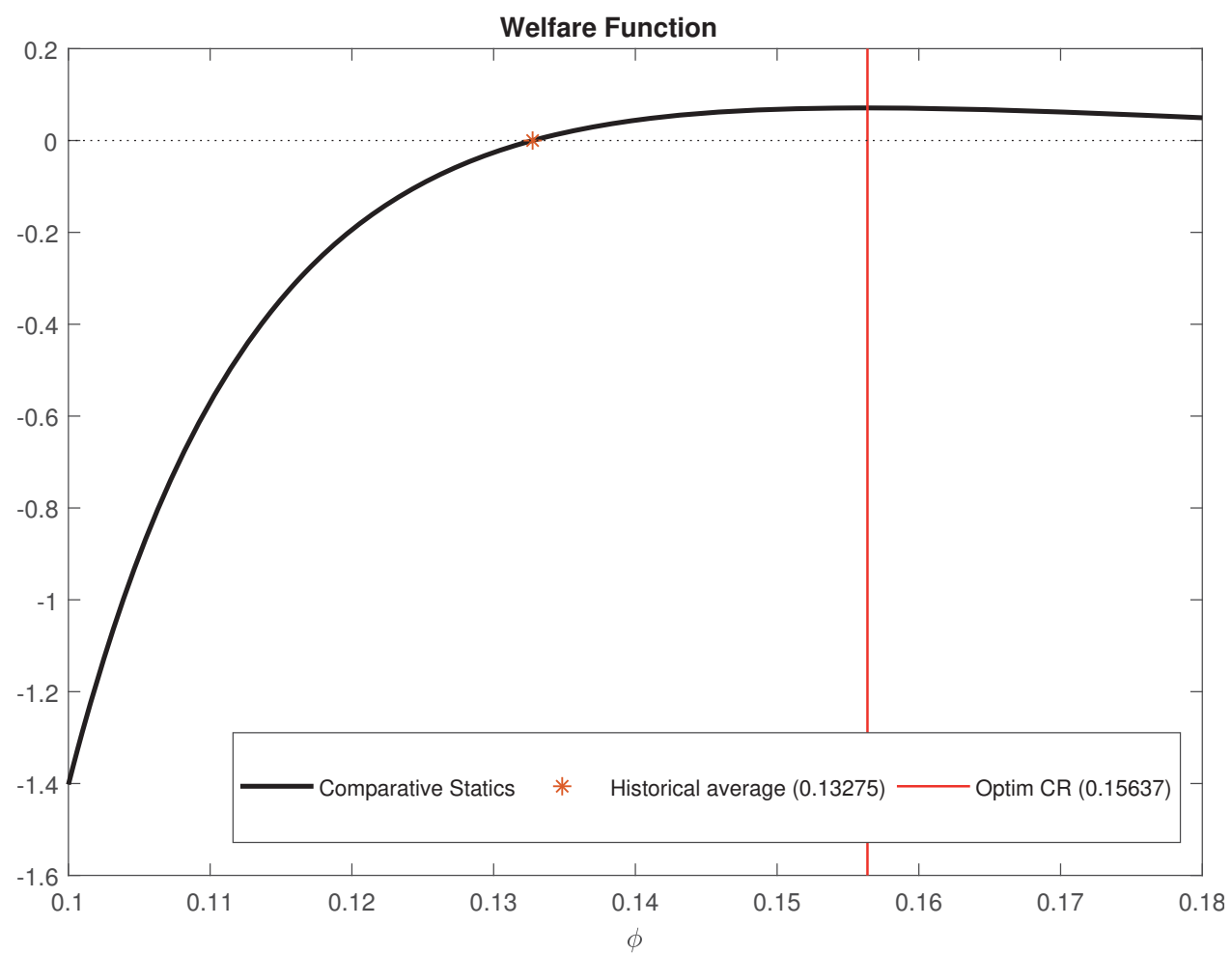

weight between corporate and commercial credit, the reduction would mainly affect corporate credit. At the optimal level of capital, banks become safer, with a default probability that is much closer to zero. The higher soundness of the financial system reduces the insurance cost, and this generates an increase in consumption and housing investment, whereas the reduction of corporate credit reduces business investment. All in all, the aggregate effect is slightly positive in terms of GDP. 
Figure 2: Economic effects from different capital levels
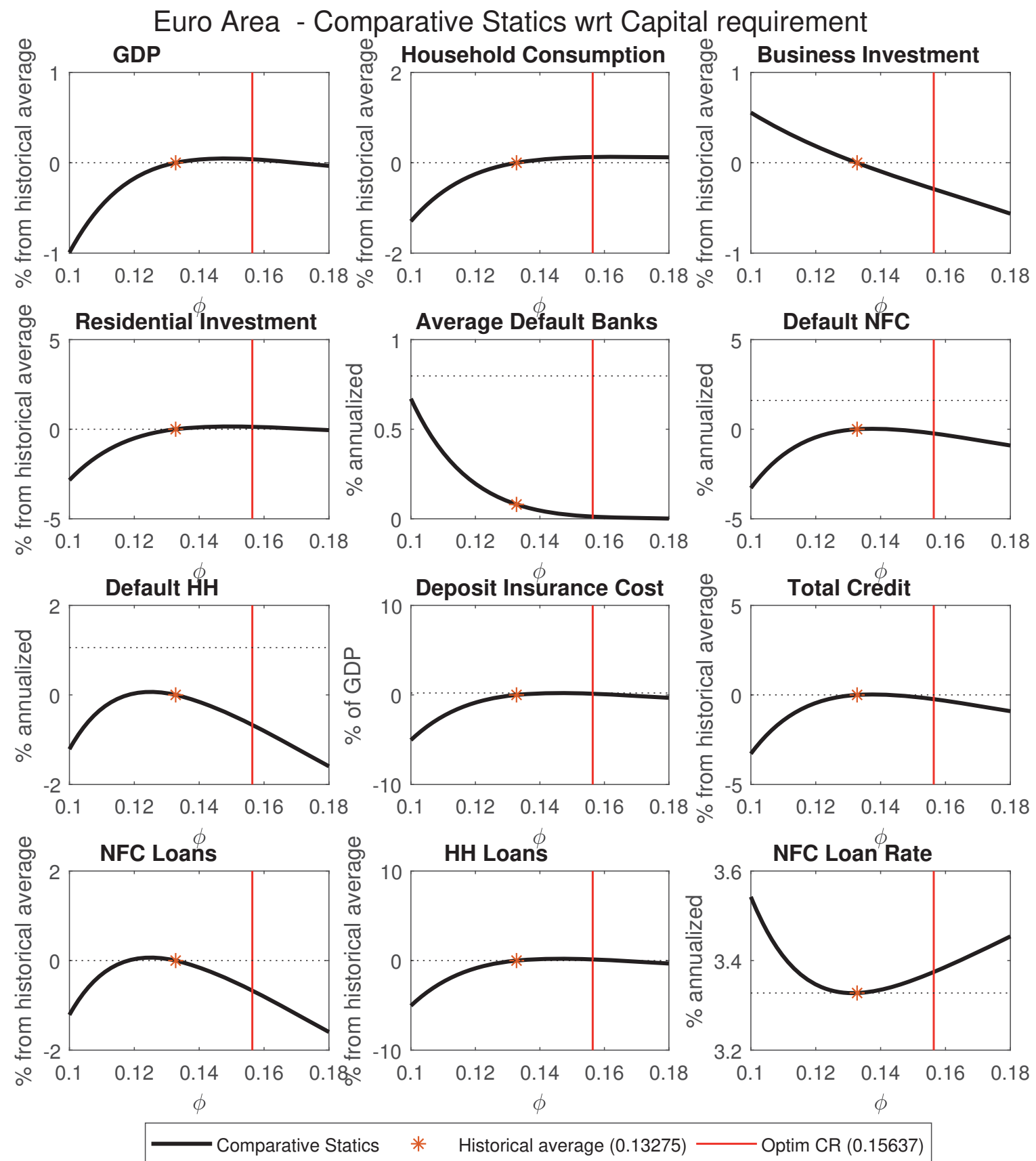

$\phi$

$\phi$

\subsubsection{Decomposition}

To help understand the trade-offs involved in attaining the optimal level, the following figure decomposes the welfare function into its four components: the terms associated to borrowers, savers, labor and (physical) capital (k) factors (always in difference from the level each one has at the observed historical average). The arguments in the welfare function have different shapes: the capital (k) factor is always increasing in capital but small in comparison to the others, while the ones for wages, borrowers and savers are all hump-shaped, but the latter in a different direction than the first two. 
Figure 3: Decomposition of the welfare function across different capital levels and shocks

Welfare function decomposition

(differences with respect to the values at the observed historical average of the capital ratio)

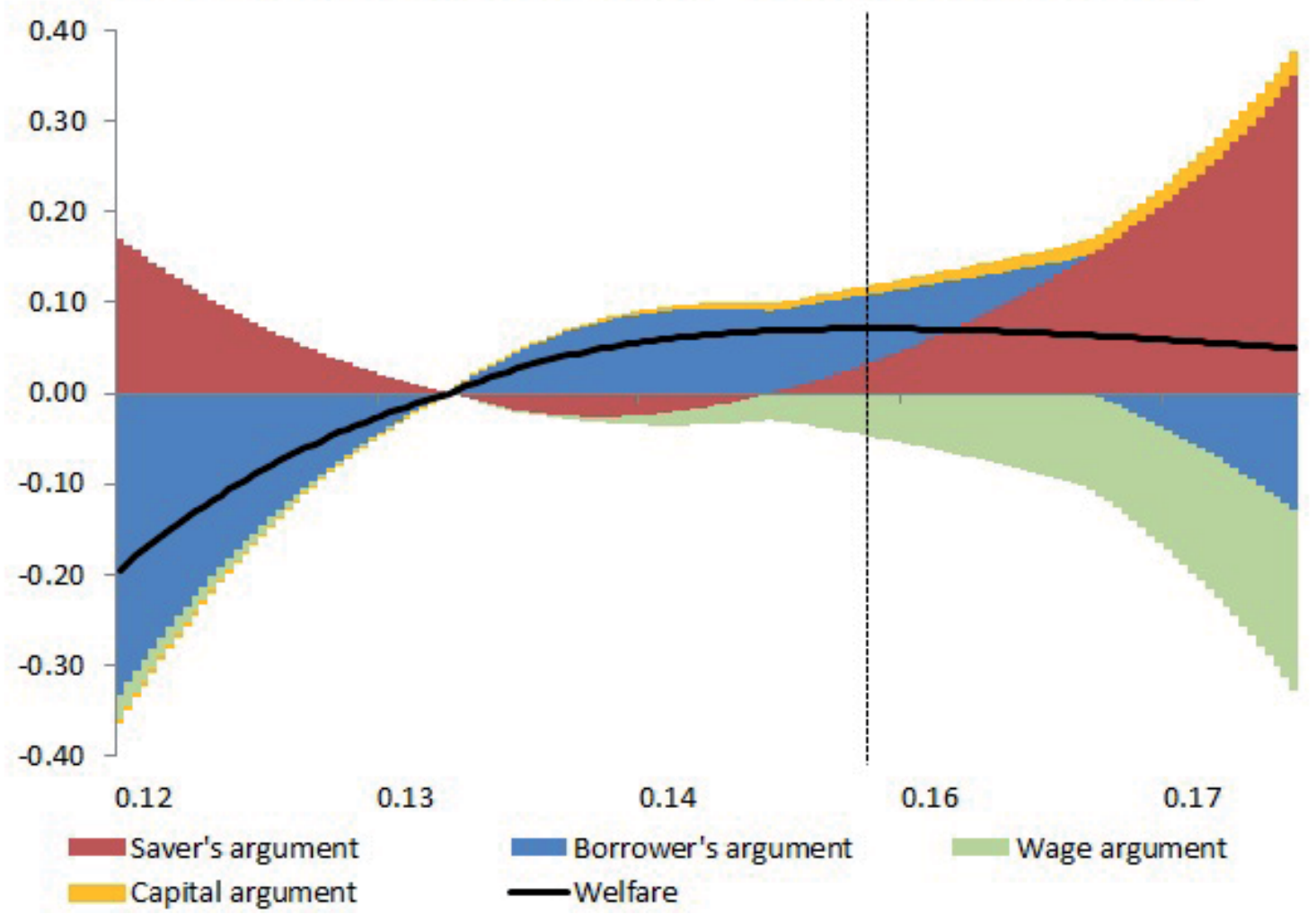

The cases of borrowers and savers are interesting to discuss (and it is easier to do so if we recall the comparative statics presented in Figure 2). When the capital ratio is relatively low, an increase has a big effect in terms of reducing the average default rate of banks, and this generates a decrease in financing costs for all agents. Therefore in this range, even if the capital rate is increasing, total credit also grows, and the welfare of borrowers is increasing. Savers, on the other hand, face both a lower interest rate and, at least initially, growing deposit insurance costs (because, although banks' average default rate is lower, total credit grows), so their welfare is decreasing. ${ }^{5}$ For high values of the capital ratio, the marginal reduction in the average default rate of banks attained by a further increase becomes smaller: the system is already very safe, and further increase in capital has bigger costs than benefits. GDP, investment and credit are decreasing, and so is the welfare of

\footnotetext{
${ }^{5}$ Note that the welfare of savers is high for very low capital levels (12) because the deposit premium is high, which more than offsets the negative externality generated by a high probability of default of banks. However, as the capital level increases, and up to levels around 15\%, the two forces invert and the negative effects from a default event more than offsets the deposit premium gains, which shrink as the bank capital requirements increase.
} 
borrowers. Financing costs rise, as credit becomes scarcer, and this increases the welfare of savers; this explains the fact that the social optimum is to the right of the maximum of the welfare of borrowers, and in a range in which the argument related to wages is clearly negative.

\subsubsection{Counterfactual scenario}

Apart from assessing the steady-state welfare effects of different levels of the capital ratio, we can also run counterfactual scenarios to see how different macro variables would have evolved in the 2001-2015 period if capital ratios had been different from the beginning.

The first step for this is to use observed data (in detrended levels), the calibrated model and the Kalman filter to construct a historical decomposition (in terms of the structural shocks in the model) of the evolution of the main macro and banking variables, in this case for the euro area in the period 2001-2014. The results in Figure 4 show that GDP and credit to households are driven mainly by real shocks, with some relevance of NFC and mortgage risk shocks in the second half of the crisis, and also bank risk shocks for a short period around 2012. Credit to firms depends much more on NFC and mortgage risk shocks, whereas the default rate of banks depends mostly on the bank risk shocks.

Using these implicit shocks we can simulate the evolution of a slightly altered version of the model where the parameter for the capital ratio is set at its optimal level. Graph 5 shows the effect, given the observed shocks, of changing this parameter. They are expressed in percentage level differences of the counterfactual simulated variables with respect to their observed evolution.

These results show that a higher capital ratio (15.6\% instead of $13.2 \%$ ) would have had a cost in terms of output and credit levels during the expansion. Yet, it would have been very effective at reducing the default rate of banks during the crisis, which in turn would have had a positive impact on credit and GDP: The total size of the crisis in terms of output, from peak to through, would have been reduced by more than one percentage point simply due to this higher bank capital requirement. 
Figure 4: Shock decomposition

Historical decomposition of Euro-area macroeconomic variables with the 3D model

Percentage deviations from steady state levels

GDP
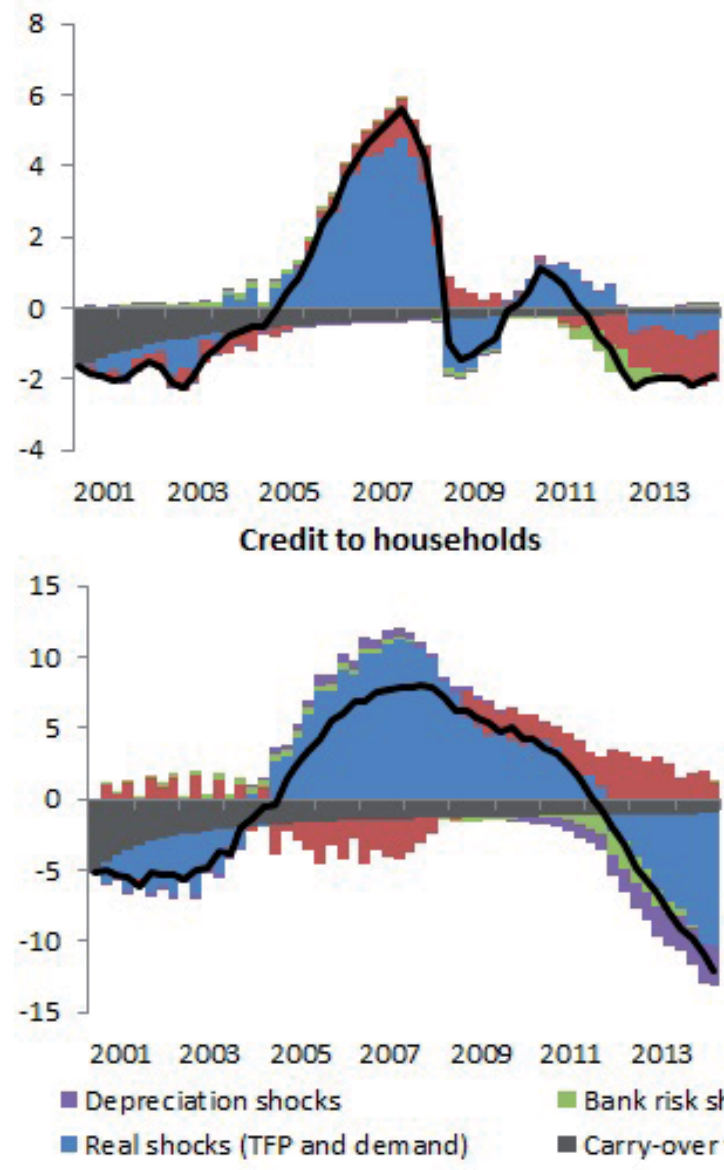

Bank default rate
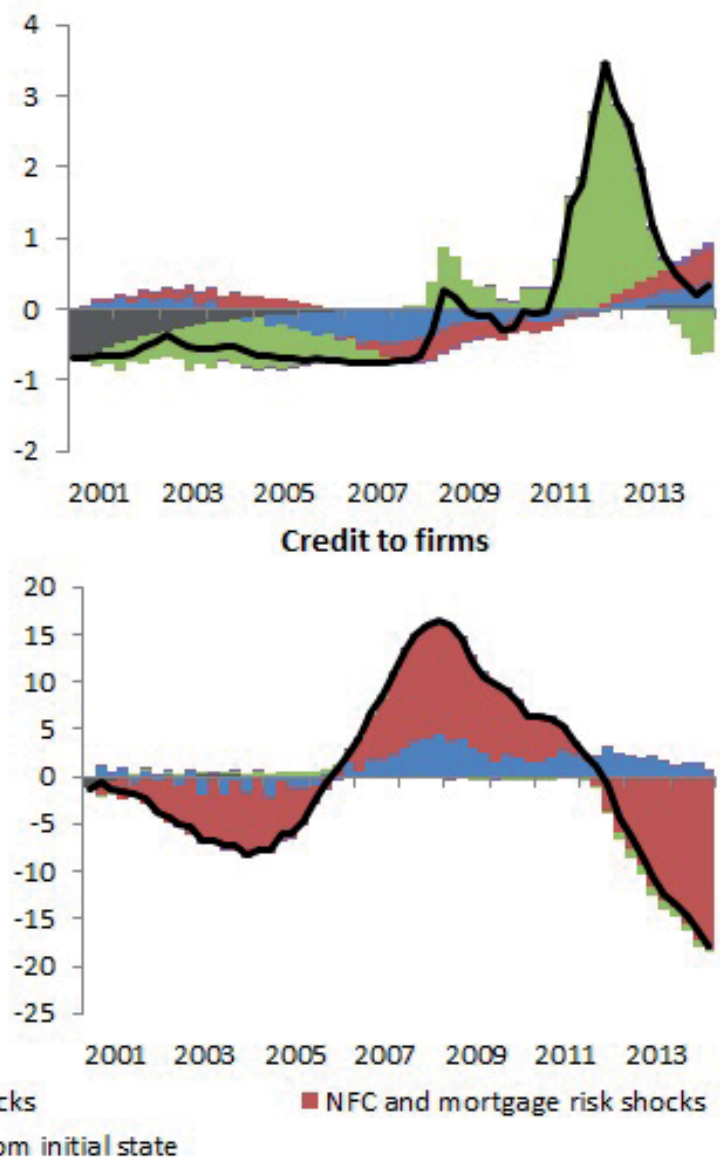

\subsection{Comparison to alternative welfare measures}

To get a broader perspective on the performance of our welfare measure, we compare it to a set of alternative measures outlined in section 2.1.3. Figure 6 shows the relative performance of our measure against alternatives. The first important thing to note is that our welfare criterion outperforms alternative (simplistic) measures since the gain in welfare from this policy is more balanced compared to the alternatives. For example, if one would to use GDP level as the underlying criterion for optimal capital level setting, then GDP, investment, and housing investment would be slightly higher compared to the level using our criterion, while credit would be significantly lower, and average default almost $20 \%$ higher. Also, optimal capital level would be $1 \%$ lower compared to the level found here. Alternatively, using the default rate as the objective criterion, the default rate would indeed be almost $10 \%$ lower compared to the level in this paper, but investment, housing investment, and GDP would be so depressed that they would be at a significantly lower level com- 
Figure 5: Difference in variables between the optimal and observed scenario

Counterfactual scenarios for the Euro area with the 3D model

Percentage level differences between the counterfactual and observed scenarios

The counterfactual model has optimal capital ratio

GDP

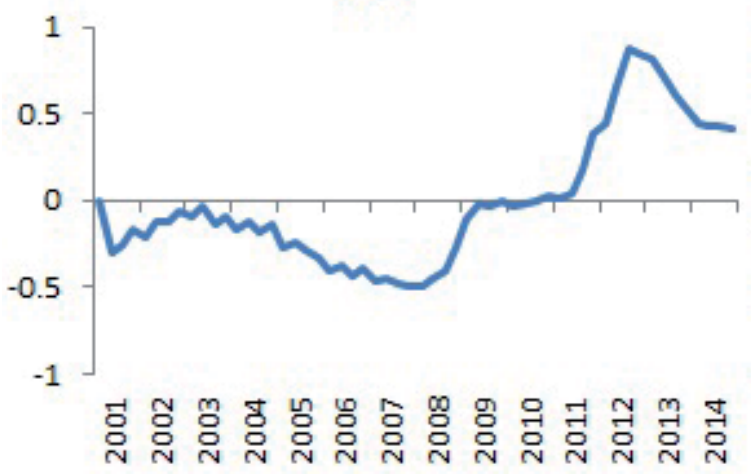

Credit to households

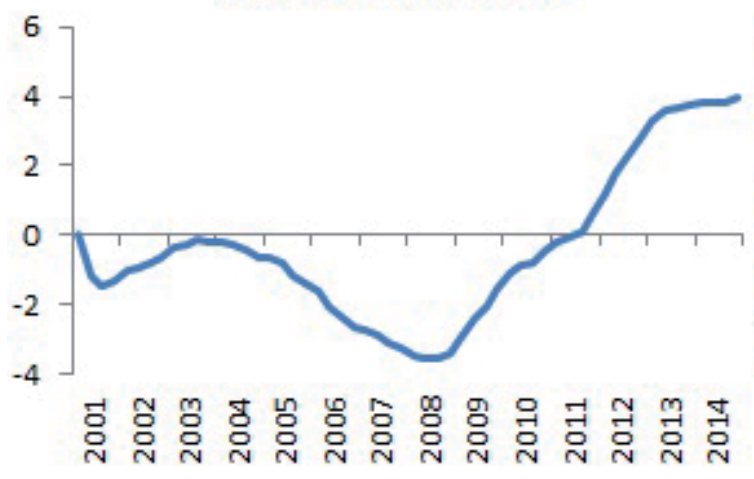

Bank default rate

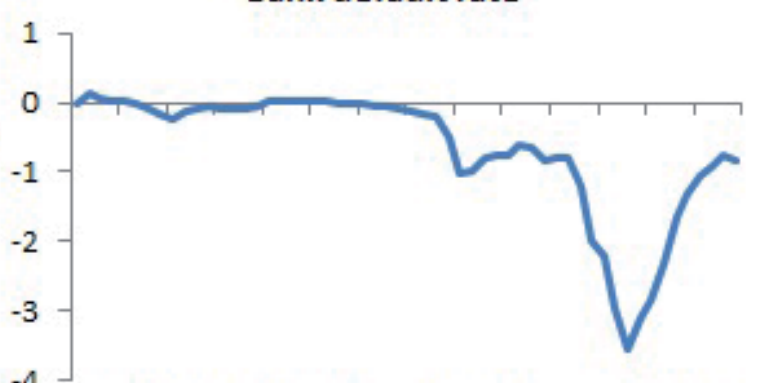

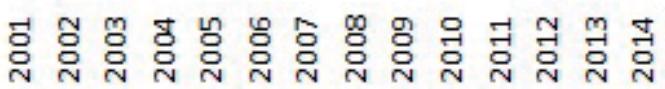
Credit to firms

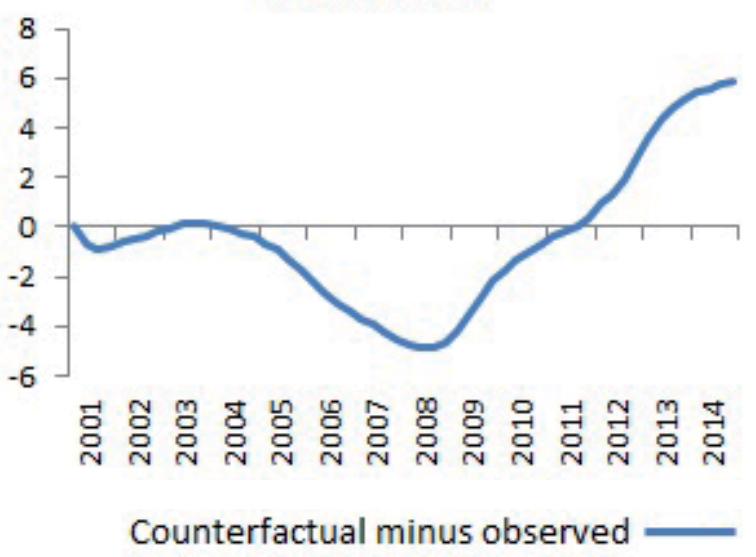

pared to what we find here. This is because for the model to further reduce average default rate compared to the optimal setting in this paper, the optimal capital level for Euro Area needs to be $2.4 \%$ higher (or at 18\%), which has highly contractionary effects on the rest of the economy. For the remaining criteria (consumption and number of crises), we find a similar pattern. In that sense, the criterion used here is much more balanced and (in relative terms) produces less economic costs compared to alternative criteria.

The other comparison we wish to make is with respect to the consumption equivalence measure of Clerc et al (2015). The graph furthest below on the left in Figure 6 compares the relative gains in welfare of using the stated welfare criterion in each column compared to $\Delta W$ used in the Clerc et al (2015) paper. ${ }^{6}$ First of all,

\footnotetext{
${ }^{6}$ In other words, the welfare using the consumption equivalence measure is the denominator in this graph and is for simplicity set to 0 . This implies that a capital level which is set using default rate as the objective function produces $0.4 \%$ higher welfare than the capital level based on consumption equivalence $\Delta W$.
} 
Figure 6: Long-run impacts on different variables using alternative welfare criteria
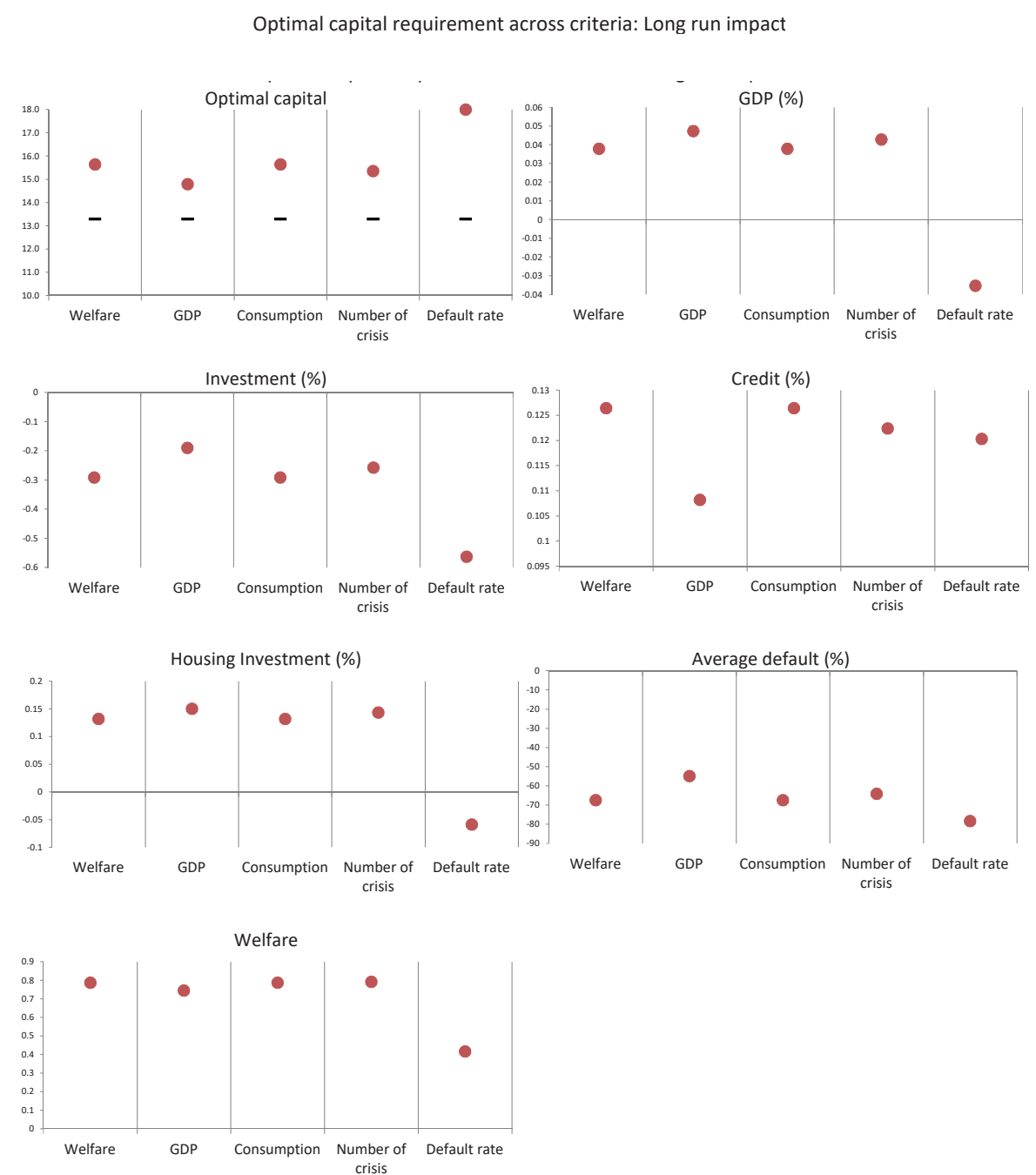

it is clear that all the welfare measures outperform the consumption equivalence measure. Second, the relative gains from using the welfare measure of this paper, together with consumption and number of crisis criterion, are highest compared to other alternatives such as GDP and default rate. Finally, note that if the policy maker wishes to use a simpler (easy to communicate) criterion, he would be as good off using the aggregate (balanced) consumption or number of crises criterion since the relative welfare gains compared to the consumption equivalence criterion are the same, and the macro-financial impacts are very close.

The reasons for the apparent outperformance of the welfare measure in this paper (and other alternatives) to the consumption equivalence lies in the limitations of the $\Delta W$ measure outlined in section 2.1.3. In particular, since the Clerc et al (2015) measure puts a higher weight on the welfare of borrowers, it does not fully take into account the trade-offs between the welfare function of borrowers and savers as one increases the capital ratio. 


\section{Optimal Countercyclical Capital Buffers}

The capital requirements ratio discussed in the previous section is a static macroprudential measure. We now turn to its dynamic counterpart: a rule for countercyclical buffers. Remember that, according to Basel III and the model set-up, countercyclical buffer is added on top of the static capital requirements, not substituting for it.

In the area of monetary policy, the Talyor rule has become a standard approach to model monetary reaction functions and a large literature has studied the general equilibrium implications of having such a rule, to which variables the optimal rule should respond to, the optimal coefficients, etc. In the context of macroprudential policy, the literature on optimal $\mathrm{CCyB}$ is much thinner, and we are far away from a consensus on whether all CCyB rules should have the same features, not to mention if there may even exist an equivalent to the 'golden rule'. Said that, we do believe that discussions and analytics relating to optimal monetary policy may be highly useful for our purposes not least because, just as a monetary policy rules, it is time-varying and responds distinctively across the cycle. Likewise, the optimal rule should balance the benefits of curbing the (financial) cycle without imposing excessive costs, and thus improving agents' total welfare. Moreover, there are good reasons for wanting to openly communicate a rule such that the public can anticipate the reaction of the central bank and anchor its expectations, just as in the case of monetary policy. The main difference, however is that $\mathrm{CCyB}$ will react to variables essential to financial stability, which have distinct data-generating process to their macroeconomic counterparts in a monetary policy rule. ${ }^{7}$

\subsection{Optimality and loss function}

$\mathrm{CCyB}$, unlike (optimal) capital requirements, is an instrument affecting the shortrun as it curbs the cycle. In other words, it only affects the dynamics around the steady state, not the steady state itself. Because of this, agents only care about the variation in their utility function arguments, where a higher (lower) variation decreases (increases) their welfare. Hence, they aim to minimise losses that are generated from variance in these variables. The optimal policy should therefore be the one that minimizes those losses. But unlike optimal capital requirements, $\mathrm{CCyB}$ rules can react to many variables and there is no obvious outright a priori candidate.

\footnotetext{
${ }^{7}$ There are currently discussions of including financial variables in monetary policy rules, and macroeconomic variables in the CCyB rules. That would bring the two closer as the sources of response would be approaching.
} 
Thus, our objective in this section is two-fold. First, to discover which rule produces the smallest loss amongst viable alternatives that involve the most relevant financial stability variables. Second, to determine the weights on each variable in the rule that generates the least loss. Both aims rely on having defined a clear and easily quantifiable loss function that is used as objective criterion in the experiments. This loss function will only contain variance terms of the variables that are fundamental to consumers' aggregate utility. As for optimal monetary policy, we obtain this loss function using the joint utility of all consumers in the model, and derive these fundamental variance terms using the model's first principles. ${ }^{8}$

\subsubsection{Deriving the second-order loss function}

We take the second order approximation to aggregate utility of consumers to derive our $\mathrm{CCyB}$ policy objective function. Since the two households are the only consumers in our setting, the policy objective function will be a weighted average of the (approximate) utility function of saver-and borrower households, or:

$$
E_{0} \sum_{i=0}^{\infty} \beta^{t+i}\left[\zeta U_{t}^{s}+(1-\zeta) U_{t}^{m}\right]
$$

where $\zeta$ is the weight of the utility of savers in the policy objective. The two utility functions are:

$$
E_{0} \sum_{i=0}^{\infty} \beta_{t+i}^{s}\left[\log c_{t+1}^{s}+\nu^{s} \log h_{t+i-1}^{s}-\frac{\varphi^{s}}{1+\eta}\left(l_{t+i}^{s}\right)^{1+\eta}\right]
$$

for savers, while for borrowers it is:

$$
E_{0} \sum_{i=0}^{\infty} \beta_{t+i}^{m}\left[\log c_{t+1}^{m}+\nu^{m} \log h_{t+i-1}^{m}-\frac{\varphi^{m}}{1+\eta}\left(l_{t+i}^{m}\right)^{1+\eta}\right]
$$

and, where $\beta^{s}>\beta^{m}$.

\footnotetext{
${ }^{8}$ Note that we are deriving a welfare optimality criterion for a quasi-linear model that is not log-linearized. By quasi-linear we imply that the model is non-linear in nature, since the default threshold gives rise to at least two states of nature, but that the jump or transition between them is smoothened via use of near-linear numerical methods. Moreover, the model includes a welfare-transfer policy that impacts the income losses and distribution absent any other policy. So, for instance, if there is a bank default, tax policy will be triggered, with subsequent welfare effects without any action on the part of the Central Bank. Considering this, the welfare criterion that is derived will assist us in finding the conditional global optimum. That is different from the unconditional optimal we find for standard linear DSGE models where there are no ex ante policy effects. Hence, the optimum that will be derived with the variance-only loss function, albeit model-consistent, micro-founded, and information efficient, may be different from optima derived using any other version of a welfare function. Nevertheless, for our CCyB purposes here, the second moment-based loss function is the correct information criterion to be used in finding the optima.
} 
We follow the methods proposed by Woodford (2003), Gali and Monacelli (2004), Chadha et al (2010), and DeFiore and Tristani (2013) to approximate their utility functions. In words of Woodford (2003), our aims of this exercise are to derive an explicit expression for the stabilization loss with which we can evaluate alternative macroprudential policies, and identify those policies that make this quantity as small as possible. This method is more convenient than other proposed in the literature, such as the optimal simple policy rule of Levine (1991) in that it is time consistent, and hence the choice of optimal rule will not depend on the initial level of the policy stance. Moreover, the loss function is fully model consistent since it is derived from the model's micro structure and it captures the total social (consumer) welfare in the model (unlike the welfare criterion of Schmitt-Grohe and Uribe, 2004).

After derivations in Appendix II, we find that the above expression can be approximated and re-written using purely quadratic additive terms:

$$
E_{0} \sum_{i=0}^{\infty} \beta^{t+i}\left(U_{t}-U\right)=-\frac{1}{2} E_{0} \Sigma_{i=0}^{\infty} \beta^{t+i} L_{t}+t . i . p+O^{3}
$$

with $L_{t}=\chi_{k} \sigma_{k}^{2}+\chi_{l^{s}} \sigma_{l^{s}}^{2}+\chi_{l^{m}} \sigma_{l^{m}}^{2}+\chi_{h^{s}} \sigma_{h^{s}}^{2}+\chi_{h^{m}} \sigma_{h^{m}}^{2}$

where $\chi_{k} \equiv Y A_{s s} \alpha\left(k_{s s}\right)^{\alpha-1}+1$,

$$
\begin{aligned}
& \chi_{l^{s}} \equiv\left((1-\alpha) l_{s s}^{s}\right)^{-\alpha}-\frac{\varphi^{s}}{1+\eta}+\frac{1+\eta}{2}, \\
& \chi_{l^{m}} \equiv\left((1-\alpha) l_{s s}^{m}\right)^{-\alpha}-\frac{\varphi^{m}}{1+\eta}+\frac{1+\eta}{2}, \\
& \chi_{h^{s}} \equiv 1+\zeta \frac{\nu^{s}}{h} h, \\
& \text { and } \chi_{h^{m}} \equiv 1+(1-\zeta) \frac{\nu^{m}}{h} h .
\end{aligned}
$$

Using the calibrated values for the Euro Area explained in the 3D model, and extracting the steady state values for the endogenous variables, we find the following optimal weights for each of the arguments in the loss function:

$$
\begin{gathered}
\chi_{k} \equiv 5,677 * 1 * 0.3 *(40,176)^{-0.7}+1=1,128 \\
\chi_{l^{s}} \equiv((1-0,3) * 1,296)^{-0,3} *-1 *(1,296)^{(1+1)} \frac{1+1}{2}=1,357 \\
\chi_{l^{m}} \equiv((1-0,3) 1,521)^{-0,3}-1 *(1,521)^{(1+1)} \frac{1+1}{2}=2,006 \\
\chi_{h^{s}} \equiv 1+0,475 * \frac{0,204}{40,786} * 40,786=1,097 \\
\chi_{h^{m}} \equiv 1+(1-0,475) * \frac{0,512}{40,786} * 40,786=1,346
\end{gathered}
$$


Normalizing to 1 for $\chi^{l_{m}}$, the respective weights become:

$$
\begin{gathered}
\chi_{k} \equiv \frac{1,128}{2,006}=0,562 \\
\chi_{l^{s}} \equiv \frac{1,357}{2,006}=0,676 \\
\chi_{l^{m}} \equiv \frac{2,006}{2,006}=1 \\
\chi_{h^{s}} \equiv \frac{1,097}{2,006}=0,546 \\
\chi_{h^{m}} \equiv \frac{1,346}{2,006}=0,670
\end{gathered}
$$

\subsection{Quantitative results}

\subsubsection{Optimal CCyB rule}

We will now try to find the optimal response rule of regulatory capital buffers to variables such as credit, housing prices and loan spreads, in order to minimize the losses generated by excessive volatility in the key model variables (described in the loss function above). We first do so while keeping the capital ratio at its calibrated value; the next section, on optimal instrument interaction, will check whether the optimal $\mathrm{CCyB}$ rule changes once the capital ratio has already shifted towards its optimum value.

It would not be feasible to try all possible functional forms for such a rule, but we will try at least the most obvious options. We will use the social loss function defined above both to find the optimal reaction parameters for each specification, and also to compare different rules once they all use their optimal parameters. As before, we conduct experiments within a calibration of the model for the Euro Area.

Our two proposed functional forms for the CCyB rule are:

$$
\begin{aligned}
& c r_{t}=\phi_{c r} c r_{f x}+\phi_{a} b_{t}+\phi_{b} q_{t}^{H} \\
& c r_{t}=\phi_{c r} c r_{f x}+\phi_{a} b_{t}+\phi_{b} R_{t}^{H}
\end{aligned}
$$

where $\phi_{c r}$ is total capital requirement at time $\mathrm{t}, c r_{f x}$ is the fixed (non-cyclical) component of the capital level, and $\phi_{a}$ and $\phi_{b}$ are the parameters that control the responses of the $\mathrm{CCyB}$ rule to the first $(a)$ and second $(b)$ arguments. All terms are expressed in deviations (gaps) from their steady state values. For each specification 
where $\phi_{c r}$ is total capital requirement at time t, $c r_{f x}$ is the fixed (non-cyclical) component of the capital level, and $\phi_{a}$ and $\phi_{b}$ are the parameters that control the responses of the $\mathrm{CCyB}$ rule to the first $(a)$ and second $(b)$ arguments. All terms are expressed in deviations (gaps) from their steady state values. For each specification we estimate the optimal value of parameters $\phi_{a}$ and $\phi_{b}$ (the responsiveness of total capital requirement to each argument in the rule) by looking for the values that minimize the social utility-based loss, as defined above. $b_{t}$ is total credit given by banks, $q_{t}^{H}$ is the housing price, and $R_{t}^{H}$ the mortgage lending spread.

The graphs below show optimal coefficients for each rule when the capital ratio is at its observed value, and the welfare gains (the reduction in the loss function) achieved by these rules.

From the Figure 7, out of the specifications that we tested, the preferred rule is the one that responds to total credit and house prices, and it does so with weights of approximately 0.3 and 0.6 respectively. The rule that responds to total credit and credit spreads should not respond to total credit.

Figure 7: Optimal CCyB rules and coefficients
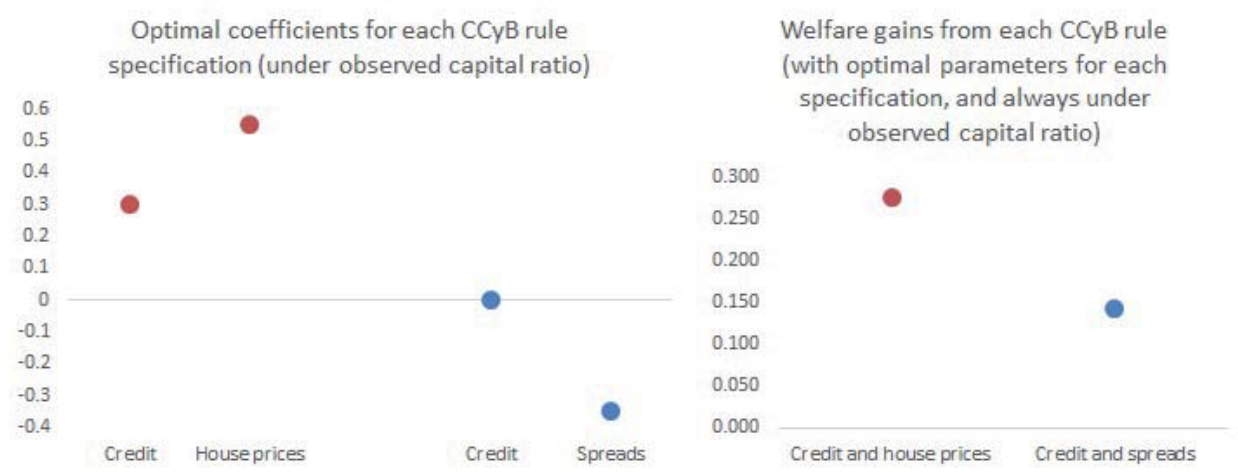

To further investigate this issue, the following graphs depict, for each functional form, the welfare gains obtained for different ranges of values of the parameters $\phi_{a}$ and $\phi_{b}$. The shaded area represents points where the rule achieves a positive welfare gain with respect to having an inactive $\mathrm{CCyB}$ policy rule. Figure 8 depicts the loss functions.

These results say that an optimal rule based on credit and house prices would tend to have balanced positive coefficients for both arguments, whereas a specification based on credit and spreads should concentrate on responding to the latter. An important result coming out of this graph is that, unlike the case of the capital ratio where there was a very wide range of values that improved welfare compared to the observed level, in the case of $\mathrm{CCyB}$ the range of values achieving welfare improvements is much narrower. 

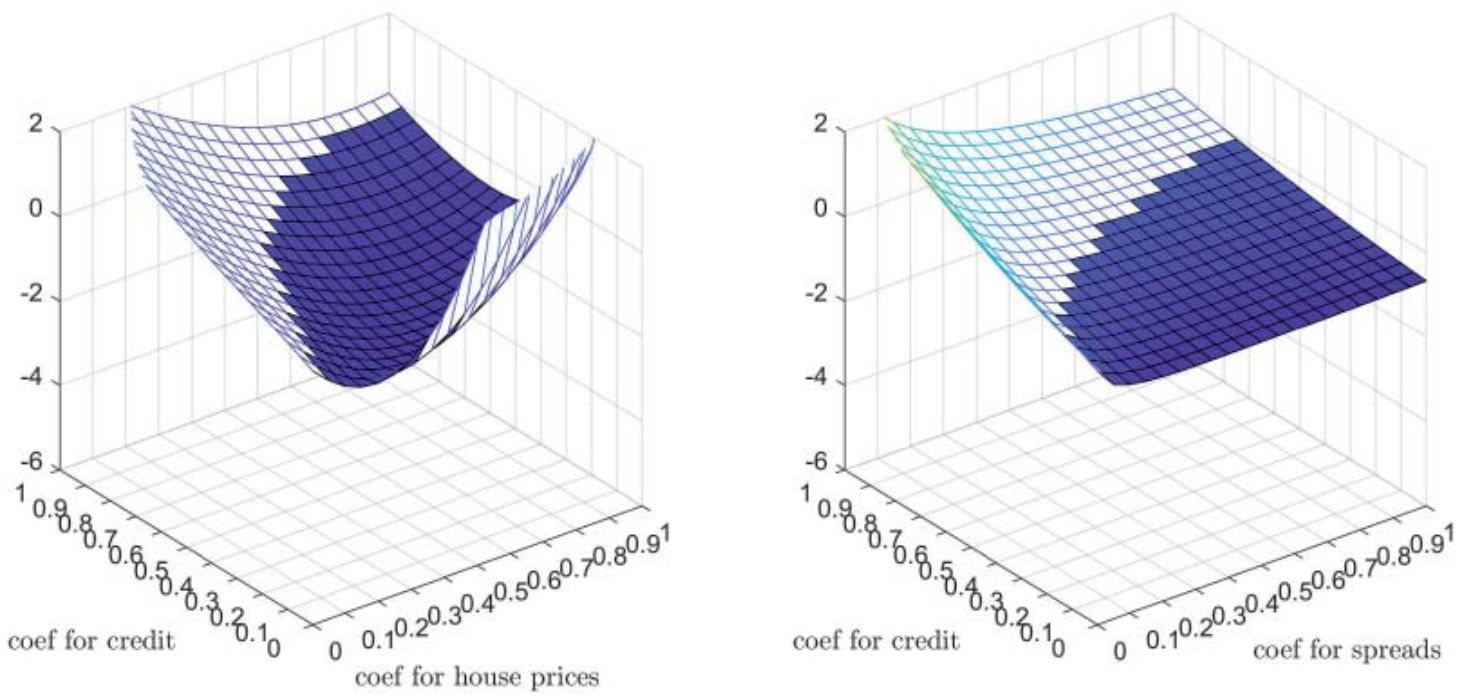

In both graphs, if we set $\phi_{b}=0$ and only allow the $\mathrm{CCyB}$ to respond to credit, we find that the optimal value of $\phi_{b}$ is also zero. This implies that CCyB rules can be a tricky policy instrument. If we consider that the policymaker has uncertainty over the model underlying the real-world economy (including its weights/coefficients) and ends up choosing a rule with mispecified (or "wrong") coefficients, it seems uncomfortably likely that this choice will result in a reduction of welfare. This could also be translated to the case of implementing one-size-fits-all policy across different economies, which, particularly in Europe, is an issue that should be investigated further.

\section{Optimal instrument interaction}

Identifying the optimal instruments in isolation can only be welfare improving within the reach of each instrument. However, as authorities are activating multiple macroprudential instruments, the desire to know their joint impact becomes higher. In this model, this is relatively straightforward as the two instruments are complements and are added on top of the other. Although operationally it is relatively simple to activate both instruments, their joint impact is not easy to pin-down analytically. In particular, since both instruments tackle financial stability and have an impact on the financial cycle, it is a priori not clear whether their effects are complementary, substituting, multiplicative, or even counteracting. Moreover, it is not apparent whether the optimal policy design may change once both instruments are triggered. To answer these questions, we would need to activate both instruments 
triggered. To answer these questions, we would need to activate both instruments while running the model and test two things. First, whether the joint impact from both optimal instruments is equal to the sum of the two effects individually. Second, to check whether there is another combination of policies (in particular another $\mathrm{CCyB}$ rule) that may generate better results. This second experiment would allow us to understand whether the individual optima remain optimal even under more complex policy environments. To run these experiments, we use the loss function defined earlier as our objective criterion to determine the optimal combination since the instruments are additive and the level of welfare cannot be improved once the basic (fixed) optimal requirement has been implemented. Thus we add the CCyB rule on top of the optimal capital requirement to examine the joint effects on losses. ${ }^{9}$

\subsection{Optimal combination of capital-based instruments}

Graphs 9 and 10 repeat the analysis of the previous section, but in a situation in which the capital ratio is already at its optimal level. With the same functional forms for the possible $\mathrm{CCyB}$ rules, the optimal rule now changes, including the optimal coefficients.

Figure 9: Optimal CCyB rules and their coefficients under alternative capital requirement scenarios
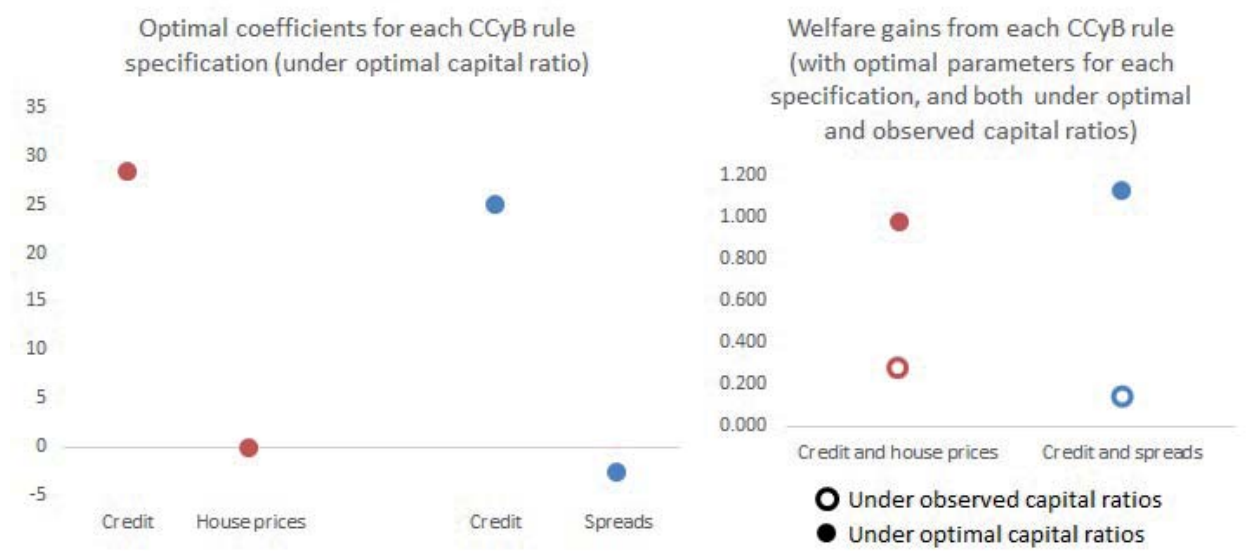

Moreover, the new level of welfare (or decrease in losses) is much higher compared to the case of only one optimal instrument, or the sum of the effects from individual optimal instruments. Moreover, with a higher capital ratio already in place, the optimal rule in this case is the one that responds to credit and spreads.

\footnotetext{
${ }^{9}$ Note that there is no need to re-optimise capital requirements since the structure and shocks in the model have not changed under this scenario. Moreover, there is no other policy that is activated which may condition the results. Thus, the optimal capital level is unconditional and cross-cutting across both situations. The only policy that may change is the CCyB as it's additive.
} 
The graphs that plot the loss function for each pair of parameters now illustrate a much bigger area of potential improvement:

This suggests that achieving a right balance in terms of the optimal capital ratio requirements (the policy instrument that affects both levels and variance of the main macro and financial variables) recognizes more space for the $\mathrm{CCyB}$ rule (the instrument that only affects the variance) to be able to achieve, in a robust manner, its own goals of reducing excessive volatility in the economy.

Figure 10: Surface of the loss function under optimal capital requirements
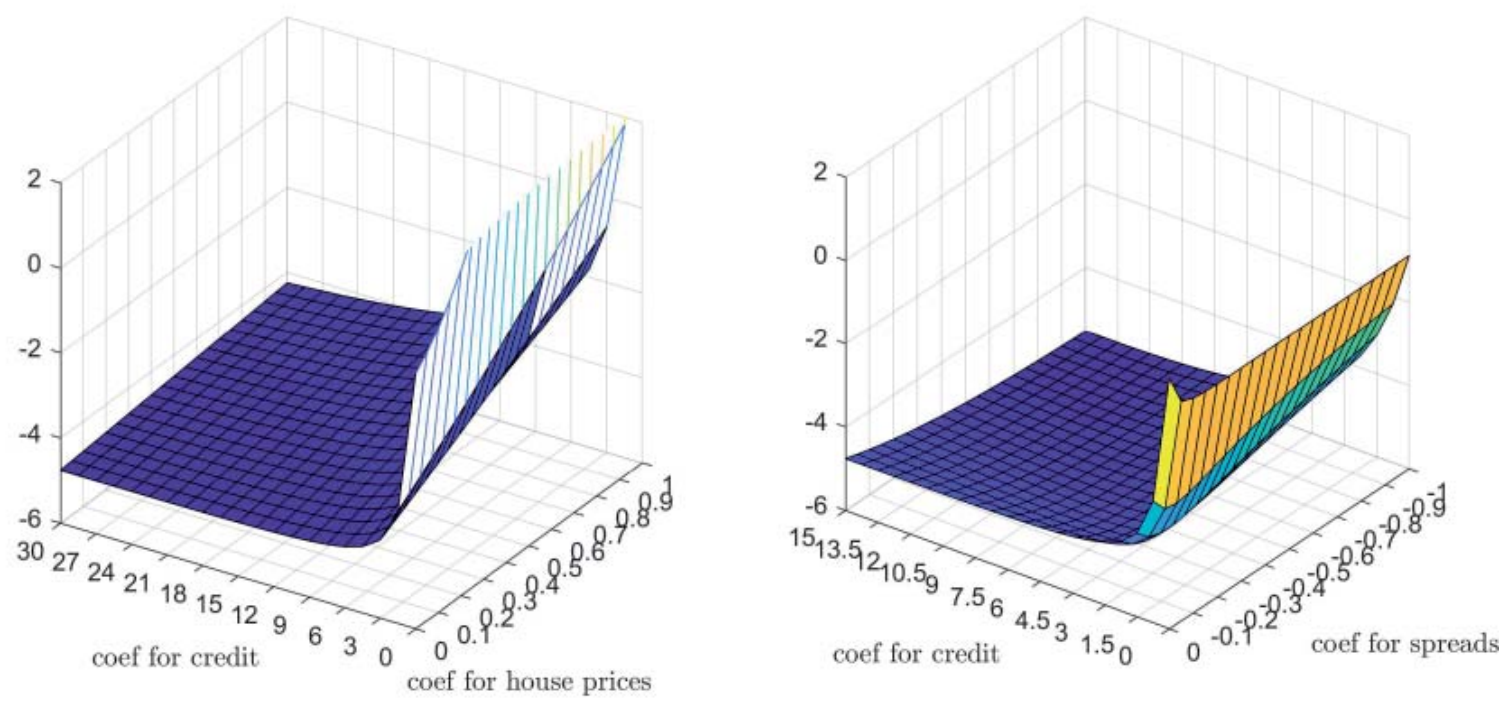

\subsection{Counterfactuals}

As we did in a previous section, we now use the historical shocks retrieved by the model to simulate, with an alternative calibration (that now includes both the optimal capital ratio and the associated optimal CCyB rule), to simulate what would have been the evolution of the economy during the recent boom and crisis if both instruments had been set optimally in 2001. As we can see in graph 11, adding the optimal CCyB rule intensifies the effects that we already saw when evaluating the effects of the optimal capital ratio, but it doesn't do this in a uniform way: the bank default rate can't be improved much farther from what the optimal capital ratio was already achieving, but on top of that the $\mathrm{CCyB}$ rule is still effective in further reducing the size of GDP and credit fluctuations (providing a higher level of these variables during the crisis, at the cost of a smaller positive deviation at the end of the boom).

To further illustrate the effects of these policies, graph 12 depicts the same results in a different way: the green lines show the observed evolution of the economy (in deviations from its calibrated steady state), and the dotted red lines present the 
counterfactual scenario with both optimal capital and optimal CCyB rule. Here we see more clearly that the financial cycle is strongly damped by these instruments, with credit deviating less from its steady state both in good and bad times, and bank default rate never even approaching the levels that it reached during the second part

Figure 11: Difference in the evolution fo the variables under various scenarios

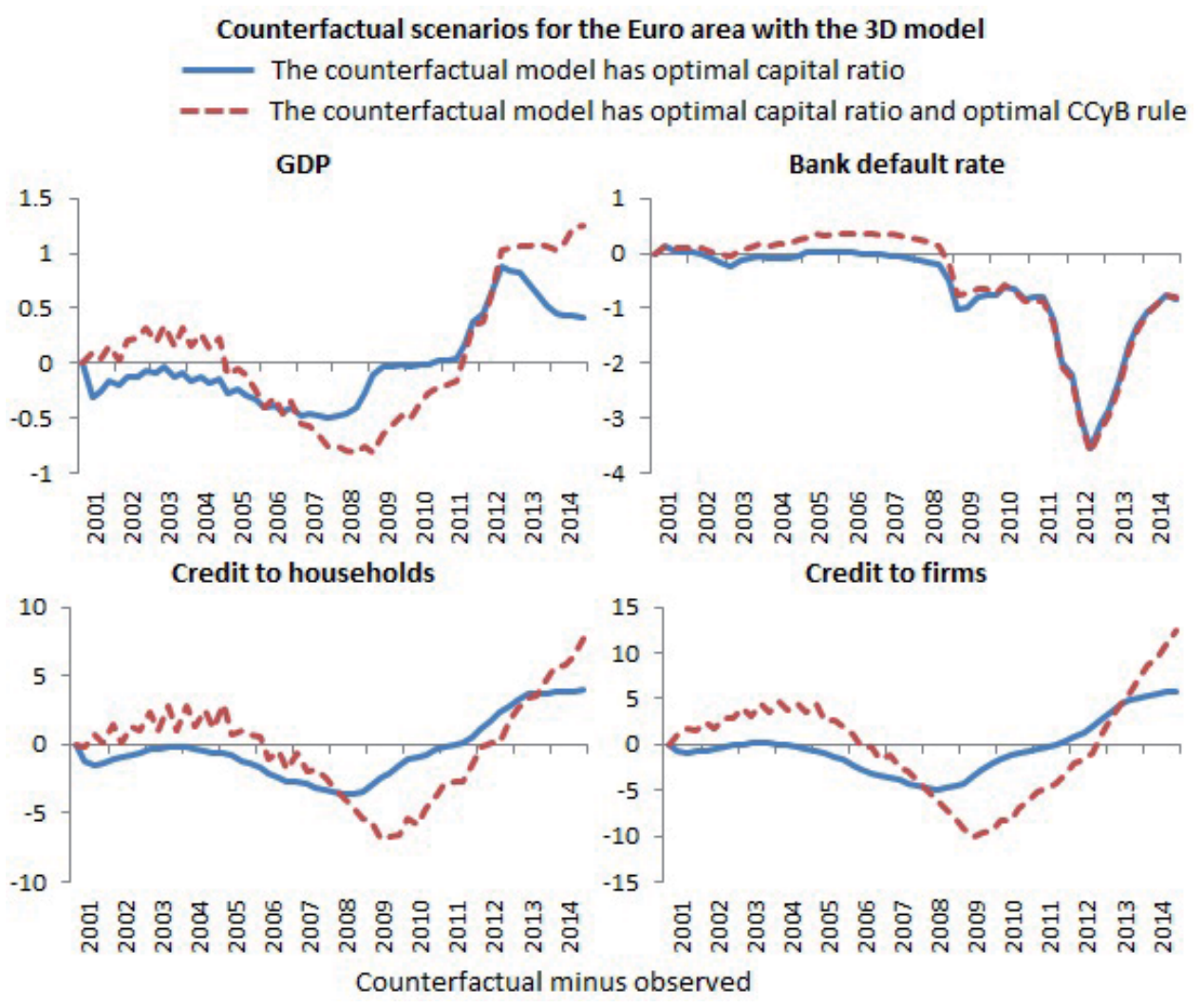

of the crisis (the reduction in the steady state level of the bank default rate achieved by the increase in the capital ratio explains the fact that the red dotted line can be always below zero: it is above its own steady state, but never reaches the levels from the original one).

The effect in terms of the real cycle (in this case, GDP) is somewhat smaller: GDP grows less during the boom and falls by less in the second half of the crisis, but the difference between the observed path and the counterfactual one is admittedly not as pronounced as in the case of credit or the default rate.

\subsection{Impulse response functions}

The main channel that explains the improved performance of the economy under optimal capital ratio and $\mathrm{CCyB}$ rules is the way it reacts to financial shocks. Graph 13 shows the IRF of the model to a bank risk shock in three different calibrations: the baseline one (black continuous line), one where the capital ratio has been set to 
Figure 12: Evolution of the various variables under realized and optimal joint instrument scenario

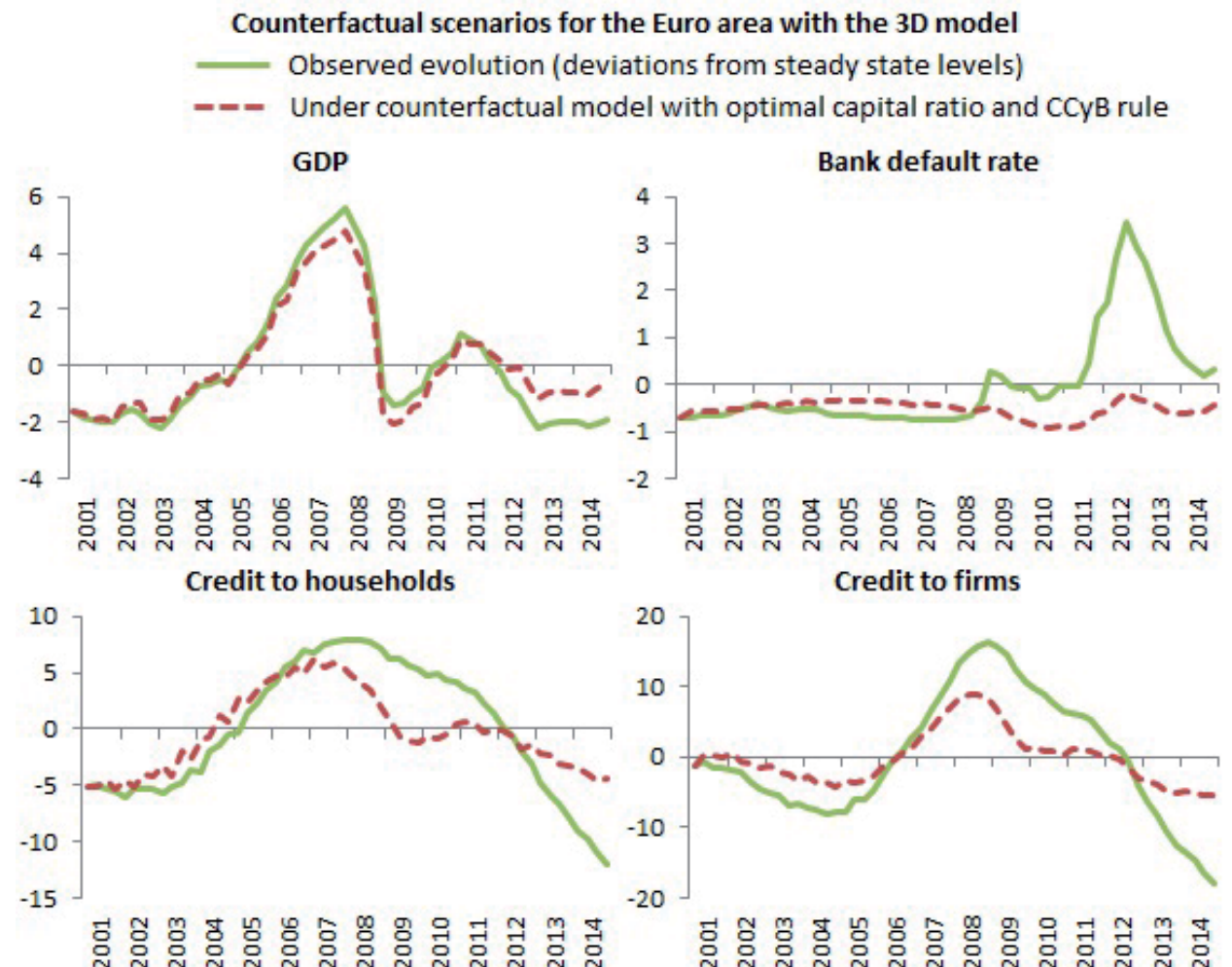

its optimal value (red dashed line) and one in which, on top of that, the optimal CCyB rule has also been implemented (blue dashed line).

Figure 13: Impulse responses under various scenarios of optimal instruments

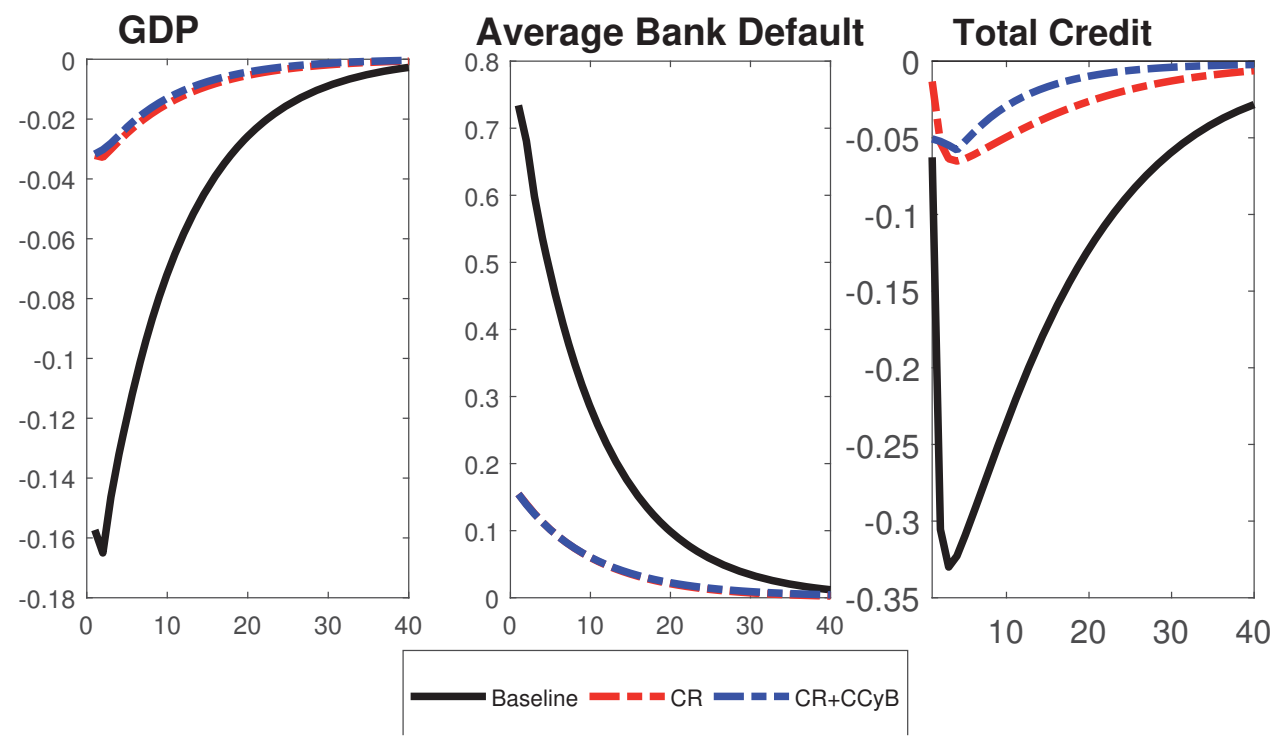


After such a shock, the model with the optimal capital ratio shows a dramatically more muted response: GDP and credit fall by much less, and bank default rate increases by much less, than in the baseline calibration. The optimal CCyB rule additionally provides a faster recovery of credit, which in turn also reduces slightly the fall in GDP; on the other hand, its additional effect on the bank default rate is found to be negligible.

\section{Conclusions}

In this paper we have provided an analytical approach to evaluating optimal macroeconomic policy rules, both in terms of capital ratio requirements and countercyclical capital buffer (CCyB) rules. As opposed to previous papers which have assessed the impact of adjusting capital requirements from a reduced-form point of view on the costs and benefits of such measures, allowing a lot of space for subjective evaluation of net benefits, our approach ponders both benefits and costs in an objective and model-consistent manner, and evaluates net benefits for the totality of the economy. In particular, we take the method developed in the monetary policy literature on optimal rules, and adapt it to the particularities of macroprudential policy. We apply this framework to the workhorse model by Clerc et al. (2015), calibrated for the euro area economy and present a case of how it can be applied.

The paper is particularly relevant for policy-makers since it provides a novel analytical avenue on how to design, calibrate, and evaluate the impact of macroprudential measures. Moreover, it provides a framework that allows regulators to compare and assess, in terms of welfare losses, how close or far away the current implemented measures are from the optimal policy. Apart from this evaluation in terms of welfare, we also compute counterfactual scenarios to show the economic performance that would have materialized had different instruments been activated in the first place.

The main results that we find are: first, the optimal level of risk-weighted capital for Euro Area is 15.6 percent. This is 2.4 percentage points higher than the average level observed during the 2001-2015 period. And we find that setting the capital level 'too high' is more forgiving than setting it 'too low': while the welfare is only marginally reduced when deviating to the right of the optimal level (overshooting), the reduction in welfare is much higher when deviating to the left (undershooting). This is important because in real time the policy-maker will always hold imperfect information regarding the contemporaneous economic structure and shocks. Second, the optimal EA CCyB rule is one that responds to developments 
in total credit and house prices. However, this result rests on the premise that the exact weights in the rule are implemented since the area of admissible coefficients is very narrow. In other words, weight misspecification can generate significant welfare costs and so great attention should be placed in applying the exact optimal weights.

Third, once an optimal capital level has been implemented, the range of permissible weights in the $\mathrm{CCyB}$ rule that expands, which reduces the probability of mispecifying the $\mathrm{CCyB}$, making it more robust. In addition, the optimal $\mathrm{CCyB}$ rule changes to one that responds to total credit and mortgage lending spreads. Also global welfare is in this case considerably higher compared to the sum of welfare gains that the two optimal policies generate separately. This means that one optimal policy exerts positive externalities on the other and generate positive synergies, which results in higher joint gains. Fourth and final, we show that, according to the model, GDPand credit losses during the Great Financial Crisis would have been significantly smaller and the default probability of banks could have been greatly reduced, had the authorities had the hindsight to implement the optimal combination of capitalbased instruments in the first place.

While we believe this paper represents an important step in formalising the design and analysis of macroprudential policies, the current framework has certain limitations. In the context of policy design, the first limitation is that we assume the authority to commit to its policy and be dynamically consistent. However, there may be occasions when the authority faces incentives to deviate from its commitment. Likewise, while we consider our results to be robust, we do not run a full set of robust policy exercises in ite pure form. Extending this work with both would be highly beneficial.

Turning to the data, it would be very interesting whether our conclusions on optimal macroprudential policy also holds for other Euro Area economies and beyond. In particular, considering the recent discussions of whether Euro Area has sufficiently converged in order to apply one policy (much like monetary policy), it would be beneficial to re-runt he same exercises for the other Euro Area economies and check whether their optimal levels and rules are similar or close to that of the Euro Area as a whole.

Finally, many countries have implemented a number of measures to tackle the negative effects from GFC, both macroprudential and others. Since many of those have spill-overs on each other and (in some cases) target the same agents, it would be interesting to examine the interaction of optimal capital-based instruments with others such as borrower-based instruments, other financial policies (such as liqpolicy. Understanding their joint impact and optimal interaction design is crucial 
for striking the right policy balance. Academic literature could and should guide the policy-makers in this direction over the coming years. Thus we believe that extending this (or any other financial frictions DSGE model) to encompass all these aspects will be a promising research avenue for the coming years. 


\section{References}

[1] Bianchi, J., and Mendoza, E. G. (2018). "Optimal time-consistent macroprudential policy" Journal of Political Economy, 126(2), 588-634.

[2] Clerc, L., Derviz, A., Mendicino, C., Moyen, S., Nikolov, K., Stracca, L., Suarez, J., and Vardoulakis, A. (2015). "Capital regulation in a macroeconomic model with three layers of default." International Journal of Central Banking, 11(3), $9-63$.

[3] De Nicol, M. G., Favara, G., and Ratnovski, L. (2012). "Externalities and macroprudential policy" International Monetary Fund.

[4] Dvila, E., and Korinek, A. (2017). "Pecuniary externalities in economies with financial frictions" The Review of Economic Studies, 85(1), 352-395.

[5] De Fiore F. and Tristani O. (2013) "Optimal Monetary Policy in a Model of the Credit Channel" The Economic Journal, 123(571): 906-931.

[6] Farhi, E., and Werning, I. (2016). "A theory of macroprudential policies in the presence of nominal rigidities" Econometrica, 84(5), 1645-1704.

[7] Ferrero, A., Harrison, R., and Nelson, B. (2018). "Concerted efforts? Monetary policy and macro-prudential tools." Bank of England Working Papers No. 727

[8] Gali J. and Monacelli T. (2005) "Monetary Policy and Exchange Rate Volatility in a Small Open Economy", Review of Economic Studies 54: 1480-1507

[9] Gerba, E. (2017) "Intangible Capital, Stock Markets, and Macroeconomic Stability: Implications for Optimal Monetary Policy", Unpublished mimeo.

[10] Mendicino, C., Nikolov, K., Suarez, J., and Supera, D. (2018). "Optimal dynamic capital requirements". Journal of Money, Credit and Banking, 50(6), 1271-1297.

[11] Mendoza, E. G. (2016). "Macroprudential policy: Promise and challenges" (No. w22868). National Bureau of Economic Research.

[12] Woodford M. (2003) Interest and Prices: Foundation of a Theory of Monetary Policy Princeton University Press, Princeton, NJ. 


\section{Appendices}

\section{Derivation of the welfare function}

Households are the only consumers in our setting. Thus, the policy objective function will be a weighted average of the (approximate) utility function of saver-and borrower households, or:

$$
E_{0} \sum_{i=0}^{\infty} \beta^{t+i}\left[\zeta U_{t}^{s}+(1-\zeta) U_{t}^{m}\right]
$$

where $\zeta$ is the weight of the utility of savers in the policy objective. The two utility functions are:

$$
E_{0} \sum_{i=0}^{\infty} \beta_{t+i}^{s}\left[\log c_{t+1}^{s}+\nu^{s} \log h_{t+i-1}^{s}-\frac{\varphi^{s}}{1+\eta}\left(l_{t+i}^{s}\right)^{1+\eta}\right]
$$

for savers, and for borrowers:

$$
E_{0} \sum_{i=0}^{\infty} \beta_{t+i}^{m}\left[\log c_{t+1}^{m}+\nu^{m} \log h_{t+i-1}^{m}-\frac{\varphi^{m}}{1+\eta}\left(l_{t+i}^{m}\right)^{1+\eta}\right]
$$

, where $\beta^{s}>\beta^{m}$.

Next, we approximate expression I.1 to first- and second order according to a standard Taylor expansion. This is an extension of the standard method used for optimal monetary policy evaluation since, beside the usual volatility effects (on the utility function), we also incorporate level effects (see e.g. Woodford (2003), Gali and Monacelli (2004), Chadha et al (2010), DeFiore and Tristani (2013), and Gerba (2017) on optimal monetary policy). This is because capital-based financial policy, unlike monetary policy, has longer-run impact on the economy. Therefore, besides the usual short-run (volatility) effects over the business cycle, this global welfare measure must also include (level) impact at a lower frequency. Note also that the choice of optimal policy rule is not dependent on the initial level of the policy stance, and is therefore time consistent.

All deviations are calculated at the steady state values and the variables marked with a tilde denote approximation up to the second order in terms of log deviations. We can express this generically by writing:

$$
\widetilde{X} \approx X\left(\widehat{X}_{t}+\frac{1}{2} \widehat{X}_{t}^{2}\right)+O^{3}
$$


with $\widehat{X}_{t}$ denoting the log-deviations of $X_{t}$ from the steady state, and the term $O^{3}$ collects all terms of order three and higher on the amplitude of the relevant shocks.

Since utility of both agents is additively separable between consumption, housing and labour (CRRA), we can consider the first- and second-order approximation to each term separately. Savers temporary utility can then be approximated as

$$
\begin{array}{r}
U_{t} \approx U+u_{c} \log \left(c^{s}\right)\left[\hat{c_{t}}+\frac{1}{2}\left(1+\frac{u_{c c} \log \left(c^{s}\right)}{u_{c}}\right) \hat{c}_{t}^{2}\right] \\
+u_{h} \nu^{s} \log \left(h^{s}\right)\left[\hat{h}_{t}+\frac{1}{2}\left(1+\frac{u_{h h} \nu^{s} \log \left(h^{s}\right)}{u_{h}}\right) \hat{h_{t}^{2}}\right] \\
-u_{l} \frac{\varphi^{s}}{1+\eta}\left(l^{s}\right)^{\eta+1}\left[\hat{l}_{t}+\frac{1}{2}\left(1+\frac{u_{l l} \frac{\varphi^{s}}{1+\eta} \log \left(l^{s}\right)^{\eta+1}}{u_{h}}\right) \hat{l_{t}^{2}}\right]
\end{array}
$$

and likewise for the utility of the borrower, we approximate it additively as:

$$
\begin{aligned}
& U_{t} \approx U+u_{c} \log \left(c^{m}\right)\left[\hat{c}_{t}+\frac{1}{2}\left(1+\frac{u_{c c} \log \left(c^{m}\right)}{u_{c}}\right) \hat{c_{t}^{2}}\right] \\
& +u_{h} \nu^{m} \log \left(h^{m}\right)\left[\hat{h_{t}}+\frac{1}{2}\left(1+\frac{u_{h h} \nu^{m} \log \left(h^{m}\right)}{u_{h}}\right) \hat{h_{t}^{2}}\right] \\
& -u_{l} \frac{\varphi^{m}}{1+\eta}\left(l^{m}\right)^{\eta+1}\left[\hat{l_{t}}+\frac{1}{2}\left(1+\frac{u_{l l} \frac{\varphi^{m}}{1+\eta}\left(l^{m}\right)^{\eta+1}}{u_{h}}\right) \hat{l_{t}^{2}}\right]
\end{aligned}
$$

The two approximations are identical except for the superscripts $s$ and $m$. Thus for the sake of space and focus, we will generically denote each variable without the superscripts in the derivations, and only reintroduce them at the end of this section. Approximating each term separately, we get that:

$$
\begin{gathered}
\log \left(c_{t}\right)=\frac{1}{c} c\left(\hat{c_{t}}+\frac{1}{2} \hat{c_{t}^{2}}\right)-\frac{1}{c^{2}} \frac{c^{2} c_{t}^{2}}{2}+O^{3}=\hat{c_{t}}+O^{3} \\
\nu \log \left(h_{t}\right)=\nu \frac{1}{h} h\left(\hat{h}_{t}+\frac{1}{2}\left({\hat{h_{t}}}^{2}\right)\right)-\frac{\nu}{h} \frac{h_{t}^{2}}{2}+O^{3}=\nu \hat{h}+O^{3}
\end{gathered}
$$

The second-order approximation to the saver's labor is given by:

$$
\frac{\varphi}{1+\eta} l_{t}=\frac{\varphi}{1+\eta} \frac{1}{l} l\left(\hat{l_{t}}+\frac{1}{2}\left(\hat{l_{t}}\right)^{2}\right)-\frac{\varphi}{(1+\eta) l^{2}} \frac{l^{2}\left(l_{t}\right)^{2}}{2}+O^{3}=\frac{\varphi}{1+\eta} \hat{l_{t}}+O^{3}
$$

\section{I.0.1 Simplifying the welfare function}

Adding equations II.7, II.8, and II.9, we get a first-and second-order approximation to the welfare function:

$$
U_{t}-U \approx \zeta\left[\hat{c}_{t}^{s}+\nu^{s} \hat{h}_{t}^{s}-\frac{\varphi^{s}}{1+\eta} \hat{l}_{t}^{s}\right]+(1-\zeta)\left[\hat{c}_{t}^{m}+\nu^{m} \hat{h}_{t}^{m}-\frac{\varphi^{m}}{1+\eta} \hat{l}_{t}^{m}\right]+O^{3}
$$


We proceed with a number of simplifications and for the moment remove all the parameters in order to facilitate the reading. Close to steady state, we have that the resource constraint is approximated by:

$$
\begin{array}{r}
Y\left(\hat{Y}_{t}+\frac{1}{2} \hat{Y}_{t}^{2}\right)=C^{s}\left(\hat{C}_{t}^{s}+\frac{1}{2}{\hat{C_{t}^{s}}}^{2}\right)+C^{m}\left(\hat{C_{t}^{m}}+\frac{1}{2}{\hat{C_{t}^{m}}}^{2}\right)+ \\
+(1+g) I\left(\hat{I}_{t}+\frac{1}{2} \hat{I}_{t}^{2}\right)+\left(1+g^{h}\right) I\left(\hat{I_{t}^{h}}+\frac{1}{2}{\hat{I_{t}^{h}}}^{2}\right)
\end{array}
$$

,which re-arranging gives:

$$
\begin{aligned}
C^{s}\left(\hat{C_{t}^{s}}+\right. & \left.\frac{1}{2}{\hat{C_{t}^{s}}}^{2}\right)+C^{m}\left(\hat{C_{t}^{m}}+\frac{1}{2}{\hat{C_{t}^{m}}}^{2}\right)=Y\left(\hat{Y}_{t}+\frac{1}{2} \hat{Y}_{t}^{2}\right)- \\
& -(1+g) I\left(\hat{I}_{t}+\frac{1}{2} \hat{I}_{t}^{2}\right)-\left(1+g^{h}\right) I^{h}\left(\hat{I_{t}^{h}}+\frac{1}{2}{\hat{I_{t}^{h}}}^{2}\right)
\end{aligned}
$$

Next, we use the (log-linear) equilibrium condition for wages:

$$
W_{t}=(1-\alpha) Y_{t}-L_{t}
$$

to further eliminate $Y_{t}$ and $L_{t}$ by approximating the above wage expression to the second order and substitute it in:

$$
(1-\alpha) Y\left(\hat{Y}_{t}+\frac{1}{2} \hat{Y}_{t}^{2}\right)-L\left(\hat{L}_{t}+\frac{1}{2} \hat{L}_{t}^{2}\right)=W\left(\hat{W}+\frac{1}{2} \hat{W}_{t}^{2}\right)
$$

and the fact that:

$$
L_{t}=L_{t}^{m}+L_{t}^{s}
$$

which at this point leaves us with:

$$
\begin{array}{r}
W\left(\hat{W}_{t}+\frac{1}{2} \hat{W}_{t}^{2}\right)+(1+g) I\left(\hat{I}_{t}+\frac{1}{2} \hat{I_{t}^{2}}\right)+\left(1+g^{h}\right) I\left(\hat{I_{t}^{h}}+\frac{1}{2}{\hat{I_{t}^{h}}}^{2}\right)+ \\
+H^{s}\left(H_{t}^{s}+\frac{1}{2} \hat{H_{t}^{s}}\right)+H^{m}\left(H_{t}^{m}+\hat{\frac{1}{2}} \hat{H}_{t}^{m^{2}}\right)
\end{array}
$$

Now we can use the housing stock- and capital stock equations to remove investment terms using:

$$
\begin{gathered}
I_{t}^{h}=H_{t}-\left(1-\delta_{t}^{h}\right) H_{t-1} \\
I_{t}=K_{t}-\left(1-\delta_{t}\right) K_{t-1}
\end{gathered}
$$

,where

$$
H_{t}=H_{t}^{m}+H_{t}^{s}
$$


We can now simplify and reduce the above expression to:

$$
\begin{aligned}
& W\left(\hat{W}_{t}+\frac{1}{2} \hat{W}_{t}^{2}\right)+(1+g) K\left(\left[\hat{K}_{t}-\left(1-\delta_{t}\right) \hat{K_{t-1}}\right]+\left[\frac{1}{2}\left[K_{t}-\left(1-\hat{\delta_{t}}\right) \quad \hat{K}_{t}\right]_{1}^{2}\right)\right]+ \\
& \left.\left(1+g^{h}\right) H\left(\left[\hat{H}_{t}-\left(1-\delta_{t}\right) \hat{H_{t-1}}\right]+\left[\frac{1}{2}\left[H_{t}-\left(1-\hat{\delta_{t}}\right) \hat{H}_{t}\right]_{1}^{2}\right)\right]+\frac{1}{2} \hat{H}_{t}^{2}\right)+H\left(\hat{H_{t-1}}+\frac{1}{2} H_{t-1}^{2}\right)
\end{aligned}
$$

Re-inserting all the parameters into the above expression, in steady state $\left(X_{t}=\right.$ $X_{t-1}=H_{s s}$ ), we can simplify, re-arrange, and collect the first-and second-order terms separately to get:

$$
\begin{array}{r}
U_{t}-U \approx\left(\zeta \frac{\nu^{s}}{h^{s}}-\frac{\left(1+g^{h}\right)}{I^{h}}\left(-\left(1-\delta^{h}\right)\right)\right) \mu_{h^{s}}+\left((1-\zeta) \frac{\nu^{m}}{h^{m}}-\frac{\left(1+g^{h}\right)}{I^{h}}\left(-\left(1-\delta^{h}\right)\right)\right) \mu_{h^{m}} \\
+\left(\frac{1+\eta}{\left(\varphi^{s}+\varphi^{m}\right)(1-\alpha) w} \frac{w^{2}}{2}\right) \mu_{w^{\eta_{t}^{2}}}-\left(\frac{1+g}{I}+\delta_{t}\right) \mu_{k}-\left(\zeta \frac{\nu^{s}}{h^{s}}-\frac{\left(1+g^{h}\right)}{I^{h}}-\left(1-\delta^{h}\right)\right) \sigma_{h^{s}}^{2} \\
+\left((1-\zeta) \frac{\nu^{m}}{h^{m}}-\frac{\left(1+g^{h}\right)}{I^{h}}-\left(1-\delta^{h}\right)\right) \sigma_{h^{m}}^{2}+\left(\frac{1+\eta}{\left(\varphi^{s}+\varphi^{m}\right)(1-\alpha) w} w\right) \sigma_{w}^{2} \\
-\left(\frac{1+g}{I} \frac{1}{2} \delta_{t}\right) \sigma_{k}^{2}-\left(\frac{1}{I} \frac{I^{2} \delta_{t}}{2}\right) \sigma_{k}^{2}+O^{3}
\end{array}
$$

where $\mu$ denotes the mean and $\sigma^{2}$ the variance terms. The expression has 4 first-order-terms and 4 second-order terms. Thus, the welfare criterion depends on the mean and variance of housing production, wages and capital, i.e. $h^{s}, h^{m}, w, k$. All the other terms that are not captured in the last expression are not relevant for policy and are collected in t.i.p. (terms independent of policy). Furthermore, we reinsert all the parameters at their appropriate place.

Now we are in a condition to rewrite the initial aggregate utility function in terms of welfare gains using the following additive welfare function with first-and second order terms:

$$
E_{0} \sum_{i=0}^{\infty} \beta^{t+i}\left(U_{t}-U\right)=E_{0} \Sigma_{i=0}^{\infty} \beta^{t+i} W^{f}+t . i . p+O^{3}
$$

with $W^{f}=\chi_{h^{s}} \mu_{h^{s}}-\chi_{h^{s}}^{2} \sigma_{h^{s}}^{2}+\chi_{h^{m}} \mu_{h^{m}}-\chi_{h^{m}}^{2} \sigma_{h^{m}}^{2}+\chi_{w} \mu_{w}-\chi_{w}^{2} \sigma_{w}^{2}+\chi_{k} \mu_{k}-\chi_{k}^{2} \sigma_{k}^{2}$ where $\chi_{h^{s}} \equiv \zeta \frac{\nu^{s}}{h^{s}}-\frac{\left(1+g^{h}\right)}{I^{h}}\left[-\left(1-\delta^{h}\right)\right]$,

$\chi_{h^{s}}^{2} \equiv \zeta \frac{\nu^{s}}{h^{s}}-\frac{\left(1+g^{h}\right)}{I^{h}}\left[-\left(1-\delta^{h}\right)\right]$,

$\chi_{h^{m}} \equiv(1-\zeta) \frac{\nu^{m}}{h^{m}}-\frac{\left(1+g^{h}\right)}{I^{h}}\left[-\left(1-\delta^{h}\right)\right]$,

$\chi_{h^{m}}^{2} \equiv(1-\zeta) \frac{\nu^{m}}{h^{m}}-\frac{\left(1+g^{h}\right)}{I^{h}}\left[-\left(1-\delta^{h}\right)\right]$,

$\chi_{w} \equiv \frac{1+\eta}{\left(\varphi^{s}+\varphi^{m}\right)(1-\alpha)} \frac{w w_{\eta_{s s}^{2}}^{2}}{2}$,

$\chi_{w}^{2} \equiv \frac{1+\eta}{\left(\varphi^{s}+\varphi^{m}\right)(1-\alpha)}$,

$\chi_{k} \equiv-\frac{1+g}{I}+\delta_{t}$,

and $\chi_{k}^{2} \equiv-\frac{1+g}{I} \frac{1}{I} \delta_{t}+\frac{1}{2} \frac{l^{2} \delta}{2}$. 
For consistency and robustness purposes, we also derived a welfare function based on the first-order approximation of the aggregate utility expression ??. Thus the expression only collects the means (levels) of the arguments. Again, the aim is to find the capital requirement that maximizes the welfare criterion. Thus, optimal is in this case defined in terms of welfare maximization. It turns out that the optimal first-order welfare function contains all the first-order terms of the full first-and second order welfare function above, such that:

$$
E_{0} \sum_{i=0}^{\infty} \beta^{t+i}\left(U_{t}-U\right)=E_{0} \sum_{i=0}^{\infty} \beta^{t+i} W_{t}^{f}+t . i . p+O^{2}
$$

$$
\begin{aligned}
& \text { with } W_{t}^{f}=\chi_{h^{s}} \mu_{h^{s}}+\chi_{h^{m}} \mu_{h^{m}}+\chi_{w} \mu_{w}+\chi_{k} \mu_{k} \\
& \text { where } \chi_{h^{s}} \equiv \zeta \frac{\nu^{s}}{h^{s}}-\frac{\left(1+g^{h}\right)}{I^{h}}-\left(1-\delta^{h}\right), \\
& \chi_{h^{m}} \equiv(1-\zeta) \frac{\nu^{m}}{h^{m}}-\frac{\left(1+g^{h}\right)}{I^{h}}-\left(1-\delta^{h}\right), \\
& \chi_{w} \equiv \frac{1+\eta}{\left(\varphi^{s}+\varphi^{m}\right)(1-\alpha)} \frac{w \eta_{s s}^{2}}{2} \\
& \text { and } \chi_{k} \equiv-\frac{1+g}{I}+\delta_{t}
\end{aligned}
$$

Using the calibrated values for the Euro Area explained in the Clerc et al (2015) paper, and extracting the steady state values for the endogenous variables, we find the following optimal weights for each of the arguments in the loss function:

$$
\begin{gathered}
\chi_{h^{s}} \equiv 3 \\
\chi_{h^{m}} \equiv 3 \\
\chi_{w} \equiv 1.43 \\
\chi_{k} \equiv-0.80
\end{gathered}
$$

Normalizing to 1 for $\chi_{h_{m}}$, the respective weights become:

$$
\begin{gathered}
\chi_{h^{s}} \equiv \frac{3}{3}=1 \\
\chi_{h^{m}} \equiv \frac{3}{3}=1 \\
\chi_{w} \equiv \frac{1.43}{3}=0.48 \\
\chi_{k} \equiv \frac{-0.8}{3}=-0.27
\end{gathered}
$$




\section{Derivation of the loss function}

Our macroprudential policy objective function is derived by taking a second order approximation to the utility of consumers in the economy. Since the two households are the only consumers in our setting, the policy objective function will be a weighted average of the (approximate) utility function of saver-and borrower households, or:

$$
E_{0} \sum_{i=0}^{\infty} \beta^{t+i}\left[\zeta U_{t}^{s}+(1-\zeta) U_{t}^{m}\right]
$$

where $\zeta$ is the weight of the utility of savers in the policy objective. The two utility functions are:

$$
E_{0} \sum_{i=0}^{\infty} \beta_{t+i}^{s}\left[\log c_{t+1}^{s}+\nu^{s} \log h_{t+i-1}^{s}-\frac{\varphi^{s}}{1+\eta}\left(l_{t+i}^{s}\right)^{1+\eta}\right]
$$

for savers, while for borrowers it is:

$$
E_{0} \sum_{i=0}^{\infty} \beta_{t+i}^{m}\left[\log c_{t+1}^{m}+\nu^{m} \log h_{t+i-1}^{m}-\frac{\varphi^{m}}{1+\eta}\left(l_{t+i}^{m}\right)^{1+\eta}\right]
$$

and, where $\beta^{s}>\beta^{m}$.

We follow the methods proposed by Woodford (2003), Gali and Monacelli (2004), Chadha et al (2010), and DeFiore and Tristani (2013) to approximate their utility functions. In words of Woodford (2003), our aims of this exercise are to derive an explicit expression for the stabilization loss with which we can evaluate alternative macroprudential policies, and identify those policies that make this quantity as small as possible. This method is more convenient than other proposed in the literature, such as the optimal simple policy rule of Levine (1991) in that it is time consistent, and hence the choice of optimal rule will not depend on the initial level of the policy stance. Moreover, the loss function is fully model consistent since it is derived from the model's micro structure and it captures the total social (consumer) welfare in the model (unlike the welfare criterion of Schmitt-Grohe and Uribe, 2004).

All deviations are calculated at the steady state values and the variables signed with a tilde denote the second order approximation in terms of log deviations. We can express this generically by:

$$
\widetilde{X} \approx X\left(\widehat{X}_{t}+\frac{1}{2} \widehat{X}_{t}^{2}\right)+O^{3}
$$

with $\widehat{X}_{t}$ denoting the log-deviations of $X_{t}$ from the steady state, and the term $O^{3}$ collects all terms of order three and higher on the amplitude of the relevant shocks. 
Since utility of both agents is additively separable between consumption, housing and labour, we can consider the second-order approximation to each term separately. Savers temporary utility can then be approximated as

$$
\begin{array}{r}
U_{t} \approx U+u_{c} \log \left(c^{s}\right)\left[\hat{c}_{t}+\frac{1}{2}\left(1+\frac{u_{c c} \log \left(c^{s}\right)}{u_{c}}\right) \hat{c_{t}^{2}}\right] \\
+u_{h} \nu^{s} \log \left(h^{s}\right)\left[\hat{h_{t}}+\frac{1}{2}\left(1+\frac{u_{h h} \nu^{s} \log \left(h^{s}\right)}{u_{h}}\right) \hat{h_{t}^{2}}\right] \\
-u_{l} \frac{\varphi^{s}}{1+\eta}\left(l^{s}\right)^{\eta+1}\left[\hat{l}_{t}+\frac{1}{2}\left(1+\frac{u_{l l} \frac{\varphi^{s}}{1+\eta} \log \left(l^{s}\right)^{\eta+1}}{u_{h}}\right) \hat{l}_{t}^{2}\right]
\end{array}
$$

and likewise for the borrower utility, we approximate additively:

$$
\begin{aligned}
& U_{t} \approx U+u_{c} \log \left(c^{m}\right)\left[\hat{c_{t}}+\frac{1}{2}\left(1+\frac{u_{c c} \log \left(c^{m}\right)}{u_{c}}\right) \hat{c_{t}^{2}}\right] \\
& +u_{h} \nu^{m} \log \left(h^{m}\right)\left[\hat{h}_{t}+\frac{1}{2}\left(1+\frac{u_{h h} \nu^{m} \log \left(h^{m}\right)}{u_{h}}\right) \hat{h_{t}^{2}}\right] \\
& -u_{l} \frac{\varphi^{m}}{1+\eta}\left(l^{m}\right)^{\eta+1}\left[\hat{l}_{t}+\frac{1}{2}\left(1+\frac{u_{l l} \frac{\varphi^{m}}{1+\eta}\left(l^{m}\right)^{\eta+1}}{u_{h}}\right) \hat{l_{t}^{2}}\right]
\end{aligned}
$$

Note thus that the two approximations are identical except for the superscripts $s$ and $m$. Thus for the sake of space and focus, we will generically denote each variable without the superscripts in the derivations, and only reintroduce them at the end of the derivations. Approximating each term separately, we get that:

$$
\begin{gathered}
\log \left(c_{t}\right)=\frac{1}{c} c\left(\hat{c_{t}}+\frac{1}{2} \hat{c_{t}^{2}}\right)-\frac{1}{c^{2}} \frac{c^{2} c_{t}^{2}}{2}+O^{3}=\hat{c_{t}}+O^{3} \\
\nu \log \left(h_{t}\right)=\nu \frac{1}{h} h\left(\hat{h}_{t}+\frac{1}{2}\left(\hat{h}_{t}{ }^{2}\right)\right)-\frac{\nu}{h} \frac{h_{t}^{2}}{2}+O^{3}=\nu \hat{h}+O^{3}
\end{gathered}
$$

The second-order approximation to the saver's labor is given by:

$$
\frac{\varphi}{1+\eta} l_{t}=\frac{\varphi}{1+\eta} \frac{1}{l} l\left(\hat{l_{t}}+\frac{1}{2}\left(\hat{l_{t}}\right)^{2}\right)-\frac{\varphi}{(1+\eta) l^{2}} \frac{l^{2}\left(l_{t}\right)^{2}}{2}+O^{3}=\frac{\varphi}{1+\eta} \hat{l_{t}}+O^{3}
$$

\section{II.0.1 Simplifying the loss function}

Adding equations II.7, II.8, and II.9, we get a second-order approximation to the welfare function:

$$
U_{t}-U \approx \zeta\left[\hat{c}_{t}^{s}+\nu^{s} \hat{h}_{t}^{s}-\frac{\varphi^{s}}{1+\eta} \hat{l}_{t}^{s}\right]+(1-\zeta)\left[\hat{c}_{t}^{m}+\nu^{m} \hat{h}_{t}^{m}-\frac{\varphi^{m}}{1+\eta} \hat{l}_{t}^{m}\right]+O^{3}
$$

We proceed with a number of simplifications. Close to steady state, we have that the resource constraint is approximated by: 
$Y\left(\hat{Y}_{t}+\frac{1}{2} \hat{Y}_{t}^{2}\right)=C^{s}\left(\hat{C}_{t}^{s}+\frac{1}{2} \hat{C}_{t}^{s^{2}}\right)+C^{m}\left(\hat{C}_{t}^{m}+\frac{1}{2}{\hat{C_{t}^{m}}}^{2}\right)+(1+g) I\left(\hat{I}_{t}+\frac{1}{2} \hat{I}_{t}^{2}\right)+\left(1+g^{h}\right) I\left(\hat{I}_{t}^{h}+\frac{1}{2}{\hat{I_{t}^{h}}}^{2}\right)$

,which re-arranging gives:

$C^{s}\left(\hat{C}_{t}^{s}+\frac{1}{2} \hat{C}_{t}^{s^{2}}\right)+C^{m}\left(\hat{C}_{t}^{m}+\frac{1}{2}{\hat{C_{t}^{m}}}^{2}\right)=Y\left(\hat{Y}_{t}+\frac{1}{2}{\hat{Y_{t}}}^{2}\right)-(1+g) I\left(\hat{I}_{t}+\frac{1}{2}{\hat{I_{t}^{2}}}^{2}\right)-\left(1+g^{h}\right) I^{h}\left({\hat{I_{t}^{h}}}^{h}+\frac{1}{2}{\hat{I_{t}^{h}}}^{2}\right)$

We use that market clearing in housing (in steady state) is:

$$
h=h^{s}+h^{m}
$$

Next, to eliminate $Y_{t}$, we use the production function:

$$
Y_{t}=A_{t} K_{t-1}^{\alpha} L_{t}^{(1-\alpha)}
$$

,which in log-linear form can be rewritten as:

$$
Y_{t}=A_{t}+\alpha K_{t-1}^{\alpha-1}+(1-\alpha) L_{t}^{-\alpha}
$$

Lastly, using the fact that investment is the difference in capital stock, and investment in housing is the difference in housing stock according to:

$$
\begin{gathered}
I_{t}=K_{t}-\left(1-\delta_{t}\right) K_{t-1} \\
I_{t}^{h}=H_{t}-\left(1-\delta_{t}^{h}\right) H_{t-1}
\end{gathered}
$$

we can use it to substitute out $I_{t}$ and $I_{t}^{h}$. Combining these, and substituting the production function for $Y$, we can write the welfare function now as:

$$
\begin{array}{r}
U_{t}-U \approx Y\left[\left[\left(A_{t}+\alpha K_{t-1}^{\alpha-1}+(1-\alpha) L_{t}^{-\alpha}\right)+\frac{1}{2}\left(A_{t}+\alpha K_{t-1}^{\alpha-1}+(1-\alpha) L_{t}^{-\alpha}\right)^{2}\right]\right. \\
-(1+g) I\left[\left(K_{t}-\left(1-\delta_{t}\right) K_{t-1}\right)+\frac{1}{2}\left(K_{t}-\left(1-\delta_{t}\right) K_{t-1}\right)^{2}-\left(1+g^{h}\right) I^{h}\left[\left(H_{t}-\left(1-\delta_{t}\right) H_{t-1}\right)\right.\right. \\
\left.+\frac{1}{2}\left(H_{t}-\left(1-\delta_{t}\right) H_{t-1}\right)^{2}\right]+\zeta\left[\frac{\nu^{s}}{h} h\left(\hat{h}_{t}^{s}+\frac{1}{2} \hat{h}_{t}^{s 2}\right)-\frac{\nu^{s}}{h^{2}} \frac{h^{2} \hat{h}_{t}^{s 2}}{2}-\frac{\varphi^{s}}{1+\eta}\left(\hat{l}_{t}^{s}+\frac{1+\eta}{2} \hat{l}_{t}^{s 2}\right)\right] \\
+(1-\zeta)\left[\frac{\nu^{m}}{h} h\left(\hat{h}_{t}^{m}+\frac{1}{2} \hat{h}_{t}^{m 2}\right)-\frac{\nu^{m 2}}{h^{2}} \frac{h^{2} \hat{h}_{t}^{m 2}}{2}-\frac{\varphi^{m}}{1+\eta}\left(\hat{l}_{t}^{m}+\frac{1+\eta}{2} \hat{l}_{t}^{m 2}\right)\right]+O^{3}
\end{array}
$$

We proceed to simplify the expression. Around the steady state, capital and housing grows at the same rate so that $k_{t-1} \approx k_{t}=h$ and $h_{t-1} \approx h_{t}=h$. Using this, and subtracting correctly the terms inside the expression, we end up with: 


$$
\begin{aligned}
U_{t}-U \approx Y\left[\left[A_{t}+\frac{1}{2}\left(A_{t}+\alpha K_{t-1}^{\alpha-1}+(1-\alpha) L_{t}^{-\alpha}\right)^{2}\right]-(1+g) I\left[\frac{1}{2}\left(K_{t}-\left(1-\delta_{t}\right) K_{t-1}\right)^{2}\right]\right. \\
\left.\left.-\left(1+g^{h}\right) I^{h}\left[\frac{1}{2}\left(H_{t}-\left(1-\delta_{t}\right) H_{t-1}\right)^{2}\right]+\zeta\left[\frac{1}{2} \hat{h}_{t}^{s 2}\right)-\frac{\varphi^{s}}{1+\eta}+\frac{1+\eta}{2} \hat{l}_{t}^{s 2}\right)\right] \\
\left.+(1-\zeta)\left[\frac{\nu^{m}}{h} h\left(\frac{1}{2} \hat{h}_{t}^{m 2}\right)-\frac{\varphi^{m}}{1+\eta}+\frac{1+\eta}{2} \hat{l}_{t}^{m 2}\right)\right]+ \text { t.i.p }+O^{3}
\end{aligned}
$$

Collecting second-order terms, using the fact that $l_{t}=l_{t}^{s}+l_{t}^{m}$ and expressing it in terms of variances, we get:

$$
\begin{array}{r}
U_{t}-U \approx \frac{1}{2}\left[\left(Y A_{s s} \alpha\left(k_{s s}\right)^{\alpha-1}+1\right) \sigma_{k}^{2}+\right. \\
+\left(\left((1-\alpha) l_{s s}^{m}\right)^{-\alpha}-\frac{\varphi^{m}}{1+\eta}+\frac{1+\eta}{2}\right) \sigma_{l^{m}}^{2}+\left(1+\zeta \frac{\nu^{s}}{h} h\right) \sigma_{h^{s}}^{2} \\
+\left(1+(1-\zeta) \frac{\nu^{m}}{h} h\right) \sigma_{h^{m}}^{2}+\text { t.i.p }+O^{3} \\
+(1+\eta
\end{array}
$$

where $\sigma^{2}$ denotes the variance terms.

Now we are in a condition to rewrite the above welfare function in terms of aggregate welfare losses using the following purely quadratic additive loss function:

$$
E_{0} \sum_{i=0}^{\infty} \beta^{t+i}\left(U_{t}-U\right)=-\frac{1}{2} E_{0} \Sigma_{i=0}^{\infty} \beta^{t+i} L_{t}+t . i . p+O^{3}
$$

with $L_{t}=\chi_{k} \sigma_{k}^{2}+\chi_{l^{s}} \sigma_{l^{s}}^{2}+\chi_{l^{m}} \sigma_{l^{m}}^{2}+\chi_{h^{s}} \sigma_{h^{s}}^{2}+\chi_{h^{m}} \sigma_{h^{m}}^{2}$

where $\chi_{k} \equiv Y A_{s s} \alpha\left(k_{s s}\right)^{\alpha-1}+1$,

$$
\begin{aligned}
& \chi_{l^{s}} \equiv\left((1-\alpha) l_{s s}^{s}\right)^{-\alpha}-\frac{\varphi^{s}}{1+\eta}+\frac{1+\eta}{2}, \\
& \chi_{l^{m}} \equiv\left((1-\alpha) l_{s s}^{m}\right)^{-\alpha}-\frac{\varphi^{m}}{1+\eta}+\frac{1+\eta}{2}, \\
& \chi_{h^{s}} \equiv 1+\zeta \frac{\nu^{s}}{h} h, \\
& \text { and } \chi_{h^{m}} \equiv 1+(1-\zeta) \frac{\nu^{m}}{h} h . \quad \text { óá }
\end{aligned}
$$




\title{
BANCO DE ESPAÑA PUBLICATIONS
}

\author{
WORKING PAPERS
}

1820 MARIO ALLOZA, PABLO BURRIEL and JAVIER J. PÉREZ: Fiscal policies in the euro area: revisiting the size of spillovers.

1821 MARTA MARTÍNEZ-MATUTE and ALBERTO URTASUN: Uncertainty, fi rm heterogeneity and labour adjustments. Evidence from European countries.

1822 GABRIELE FIORENTINI, ALESSANDRO GALESI, GABRIEL PÉREZ-QUIRÓS and ENRIQUE SENTANA: The rise and fall of the natural interest rate.

1823 ALBERTO MARTÍN, ENRIQUE MORAL-BENITO and TOM SCHMITZ: The fi nancial transmission of housing bubbles: evidence from Spain.

1824 DOMINIK THALER: Sovereign default, domestic banks and exclusion from international capital markets.

1825 JORGE E. GALÁN and JAVIER MENCÍA: Empirical assessment of alternative structural methods for identifying cyclical systemic risk in Europe.

1826 ROBERTO BLANCO and NOELIA JIMÉNEZ: Credit allocation along the business cycle: evidence from the latest boom bust credit cycle in Spain.

1827 ISABEL ARGIMÓN: The relevance of currency-denomination for the cross-border effects of monetary policy.

1828 SANDRA GARCÍA-URIBE: The effects of tax changes on economic activity: a narrative approach to frequent anticipations.

1829 MATÍAS CABRERA, GERALD P. DWYER and MARÍA J. NIETO: The G-20 regulatory agenda and bank risk.

1830 JACOPO TIMINI and MARINA CONESA: Chinese exports and non-tariff measures: testing for heterogeneous effects at the product level.

1831 JAVIER ANDRÉS, JOSÉ E. BOSCÁ, JAVIER FERRI and CRISTINA FUENTES-ALBERO: Households' balance sheets and the effect of fiscal policy.

1832 ÓSCAR ARCE, MIGUEL GARCÍA-POSADA, SERGIO MAYORDOMO and STEVEN ONGENA: Adapting lending policies when negative interest rates hit banks' profits.

1833 VICENTE SALAS, LUCIO SAN JUAN and JAVIER VALLÉS: Corporate cost and profit shares in the euro area and the US: the same story?

1834 MARTÍN GONZÁLEZ-EIRAS and CARLOS SANZ: Women's representation in politics: voter bias, party bias, and electoral systems.

1835 MÓNICA CORREA-LÓPEZ and BEATRIZ DE BLAS: Faraway, so close! Technology diffusion and firm heterogeneity in the medium term cycle of advanced economies.

1836 JACOPO TIMINI: The margins of trade: market entry and sector spillovers, the case of Italy (1862-1913).

1837 HENRIQUE S. BASSO and OMAR RACHEDI: The young, the old, and the government: demographics and fiscal multipliers.

1838 PAU ROLDÁN and SONIA GILBUKH: Firm dynamics and pricing under customer capital accumulation.

1839 GUILHERME BANDEIRA, JORDI CABALLÉ and EUGENIA VELLA: Should I stay or should I go? Austerity, unemployment and migration.

1840 ALESSIO MORO and OMAR RACHEDI: The changing structure of government consumption spending.

1841 GERGELY GANICS, ATSUSHI INOUE and BARBARA ROSSI: Confidence intervals for bias and size distortion in IV and local projections - IV models.

1842 MARÍA GIL, JAVIER J. PÉREZ, A. JESÚS SÁNCHEZ and ALBERTO URTASUN: Nowcasting private consumption: traditional indicators, uncertainty measures, credit cards and some internet data.

1843 MATÍAS LAMAS and JAVIER MENCÍA: What drives sovereign debt portfolios of banks in a crisis context?

1844 MIGUEL ALMUNIA, POL ANTRÀS, DAVID LÓPEZ-RODRÍGUEZ and EDUARDO MORALES: Venting out: exports during a domestic slump.

1845 LUCA FORNARO and FEDERICA ROMEI: The paradox of global thrift.

1846 JUAN S. MORA-SANGUINETTI and MARTA MARTÍNEZ-MATUTE: An economic analysis of court fees: evidence from the Spanish civil jurisdiction.

1847 MIKEL BEDAYO, ÁNGEL ESTRADA and JESÚS SAURINA: Bank capital, lending booms, and busts. Evidence from Spain in the last 150 years.

1848 DANIEL DEJUÁN and CORINNA GHIRELLI: Policy uncertainty and investment in Spain. 
1849 CRISTINA BARCELÓ and ERNESTO VILLANUEVA: The risk of job loss, household formation and housing demand: evidence from differences in severance payments.

1850 FEDERICO TAGLIATI: Welfare effects of an in-kind transfer program: evidence from Mexico.

1851 ÓSCAR ARCE, GALO NUÑO, DOMINIK THALER and CARLOS THOMAS: A large central bank balance sheet? Floor vs corridor systems in a New Keynesian environment.

1901 EDUARDO GUTIÉRREZ and ENRIQUE MORAL-BENITO: Trade and credit: revisiting the evidence.

1902 LAURENT CAVENAILE and PAU ROLDAN: Advertising, innovation and economic growth.

1903 DESISLAVA C. ANDREEVA and MIGUEL GARCÍA-POSADA: The impact of the ECB's targeted long-term refinancing operations on banks' lending policies: the role of competition.

1904 ANDREA ALBANESE, CORINNA GHIRELLI and MATTEO PICCHIO: Timed to say goodbye: does unemployment benefit eligibility affect worker layoffs?

1905 CORINNA GHIRELLI, MARÍA GIL, JAVIER J. PÉREZ and ALBERTO URTASUN: Measuring economic and economic policy uncertainty, and their macroeconomic effects: the case of Spain.

1906 CORINNA GHIRELLI, JAVIER J. PÉREZ and ALBERTO URTASUN: A new economic policy uncertainty index for Spain.

1907 ESTEBAN GARCÍA-MIRALLES, NEZIH GUNER and ROBERTO RAMOS: The Spanish personal income tax: facts and parametric estimates.

1908 SERGIO MAYORDOMO and OMAR RACHEDI: The China syndrome affects banks: the credit supply channel of foreign import competition

1909 MÓNICA CORREA-LÓPEZ, MATÍAS PACCE and KATHI SCHLEPPER: Exploring trend inflation dynamics in Euro Area countries.

1910 JAMES COSTAIN, ANTON NAKOV and BORJA PETIT: Monetary policy implications of state-dependent prices and wages.

1911 JAMES CLOYNE, CLODOMIRO FERREIRA, MAREN FROEMEL and PAOLO SURICO: Monetary policy, corporate finance and investment.

1912 CHRISTIAN CASTRO and JORGE E. GALÁN: Drivers of productivity in the Spanish banking sector: recent evidence.

1913 SUSANA PÁRRAGA RODRÍGUEZ: The effects of pension-related policies on household spending.

1914 MÁXIMO CAMACHO, MARÍA DOLORES GADEA and ANA GÓMEZ LOSCOS: A new approach to dating the reference cycle.

1915 LAURA HOSPIDO, LUC LAEVEN and ANA LAMO: The gender promotion gap: evidence from Central Banking.

1916 PABLO AGUILAR, STEPHAN FAHR, EDDIE GERBA and SAMUEL HURTADO: Quest for robust optimal macroprudential policy.

BANCODEESPAÑA Eurosistema
Unidad de Servicios Auxiliares

Alcalá, 48 - 28014 Madrid

E-mail: publicaciones@bde.es www.bde.es 